القزاز: الرسوم اليدوية قبالة الرسوم الحاسوبية في طور التصميم المعماري المفاهيمي

\begin{abstract}
الرسوم اليدوية قبالة الرسوم الحاسوبية في طور التصميم المعماري المفاهيمي
د. ضحى عبد الغتي عبد العزيز القزاز

مدرس في قسم الهندسة المعمارية / جامعة الموصل الميز

الخلاصة المعارة

في السنوات الأخيرة، يُطرح الجدل في الأوساط المعمارية الأكاديمية وغير الأكاديمية حول قيمة الرسوم اليدوية

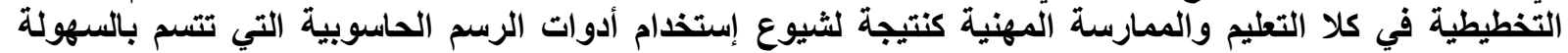
النسبية في تمثيل وإظهار وإدراك التصميم بإستخدام تقنيات حاسوبية كبرمجيات القولبة البارامترية والنمذية التية النية السريعة.

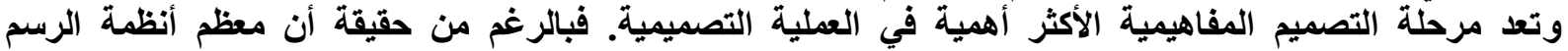
الحاسوبية أمثال AutoCAD و

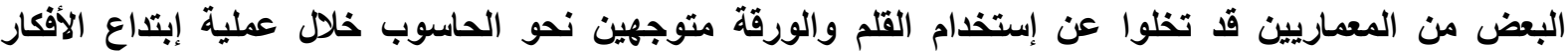
التصميمية.

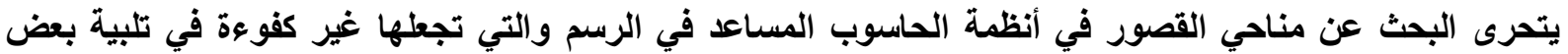

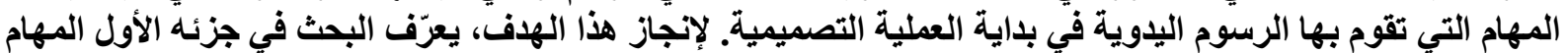

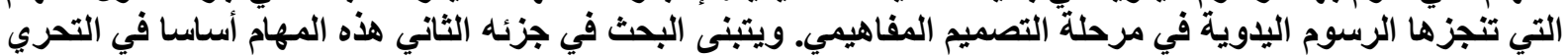

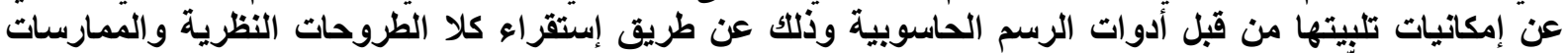

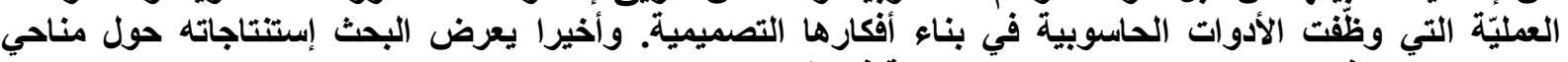

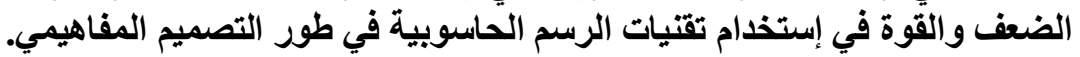

الكلمات الدالة: الرسوم اليدوية، الرسوم التخطيطية، الرسوم الحاسوبية، مرحلة التصميم المفاهيمي ـ

\section{Freehand Drawings versus CAD Drawings in the Conceptual Architectural Design Phase}

\author{
Dr. Dhuha Abdulgani Abdulaziz Al-kazzaz \\ Lecturer in Dept. of Architectural Engineering / University of Mosul
}

Abstract:

In the last decade, the value of freehand drawing as a design tool in both education and practice is open to debate as a result of the accessibility of digitised drawing tools such as CAD systems and the relative ease with which a design can be presented and realised using computerised techniques such as parametric modelling and rapid prototyping. The conceptual design stage is the most critical in the design process. Despite the fact that most of the widespread computer aided design systems (such as AutoCAD and 3DSMax) are primarily directed towards the more detailed stage of design process. Even so, there are architects today who have abandoned the use of a pencil and paper, turning to the computer during the creation of their design concepts.

The paper investigates the limitations of Computer Aided Drawing (CAD) systems which make them unable to satisfy what freehand drawings are doing for the initial design phase. To achieve this aim, the first section of this paper puts forward a framework for the main roles of freehand drawings through the conceptual design process. The second section investigates the capabilities of computer aided drawing tools to achieve these roles by depending on the theory and practice of the use of CAD tools at the initial design stage. The third section concludes the weakness and strength of computer aided drawing systems in the conceptual design phase. The paper ends with recommendations.

Keywords: freehand drawings; sketches, CAD drawings; conceptual design phase 


\section{1. المقدمة: الحاسوب المساعد في الرسم (الكاد) بدلا من الرسوم اليدوية_ــالمخاوف والهواجس}

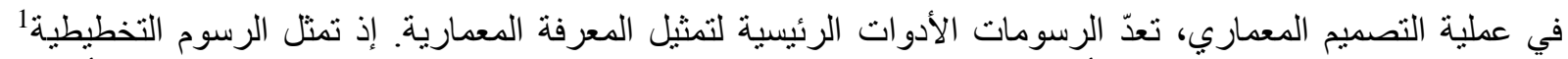
sketches

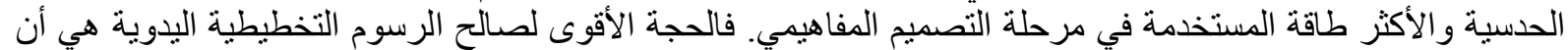

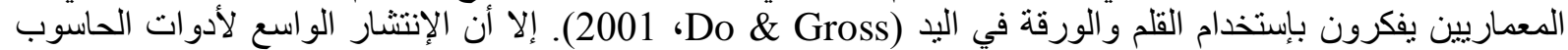

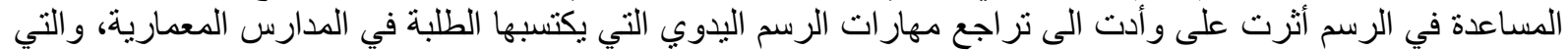

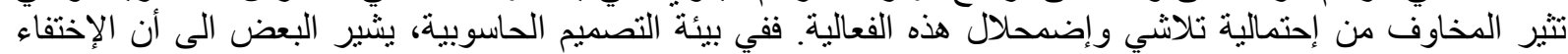

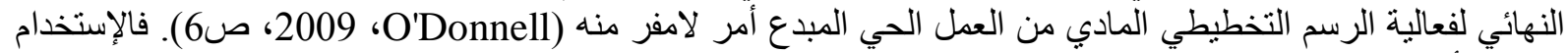

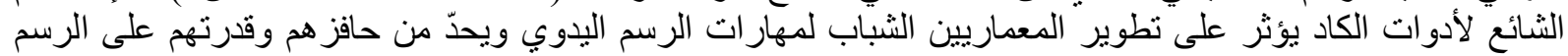

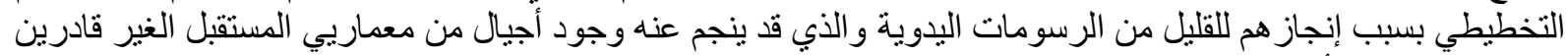

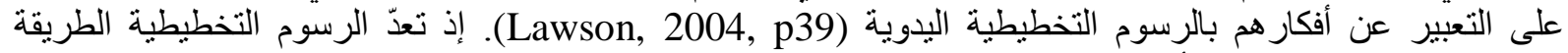

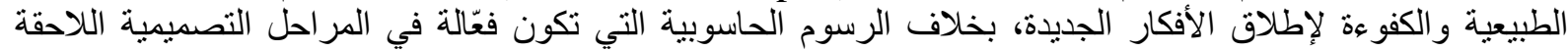

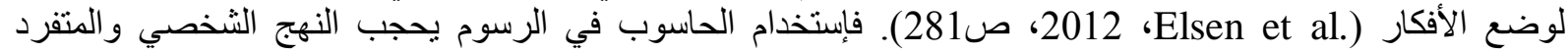

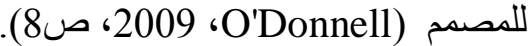

ويشير . Elsen et al الى مشكلة تقليص التركيز على فعالية الرسم التخطيطي اليدوي، معتبر ا "أنها تبقى الأداة الحاسمة

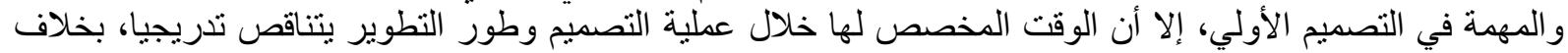

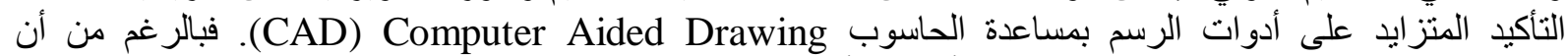

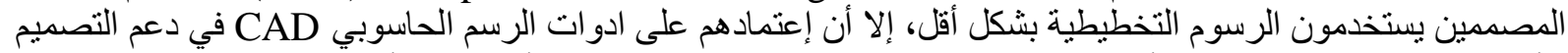

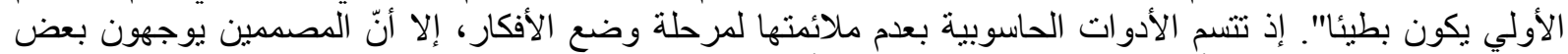

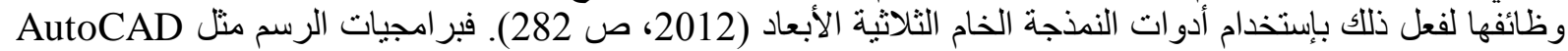

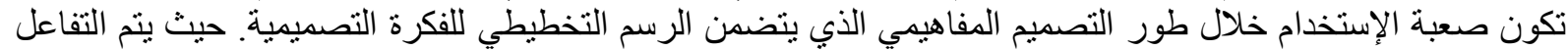

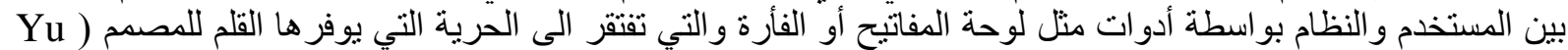
المطول \&hang

المعلومات حول التصميم (200). فلى (Masry \& Lipson، 2005).

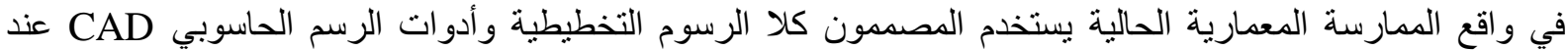

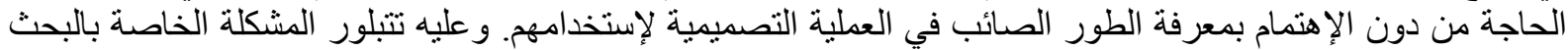

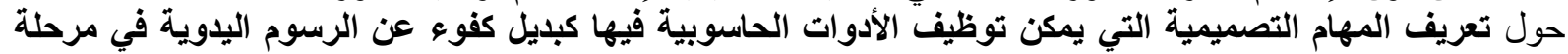
بناء الأفكار التصميمية.

يستعرض البحث في الفقرة التالية الأدبيات التي تناولت الأدوار الإيجابية والسلبية لأدوات الرسم الليدوية والحاسوبية المستخدمة في عملية التصميم المفاهيمي لإستخلاص مناحي القوة و الضعف في كل منهما.

$$
\text { 2. أدوات الرسم اليدوية والحاسوبية ــ المزايا وأوجه القصور }
$$

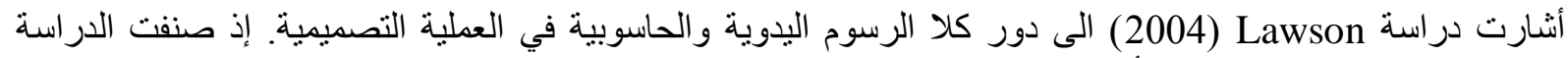

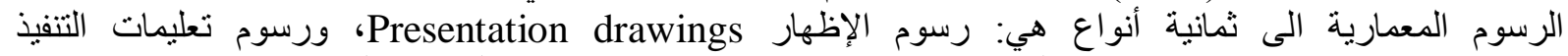

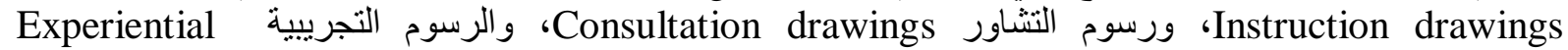
drawings، و الرسوم التوضيحية Diagrams، والرسوم الرائعة Fabulous drawings، و الرسوم الإفتراضية

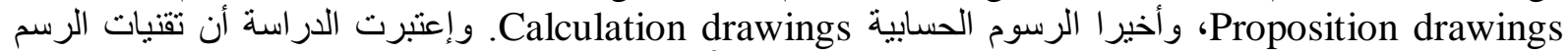

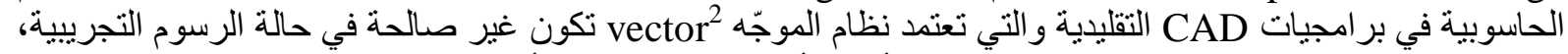

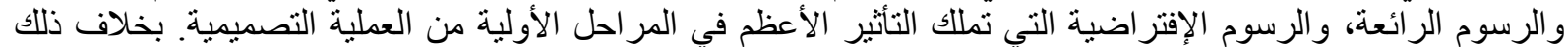

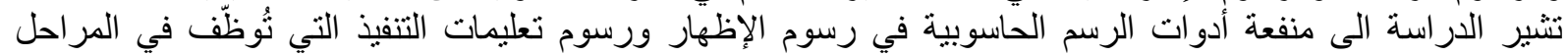

1 يستخدم البحث مصطلح الرسوم التخطيطية للإشارة الى مفهوم Sketches.

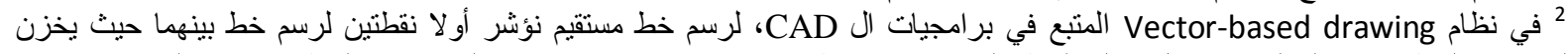

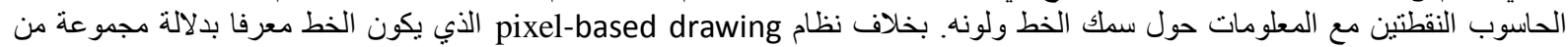




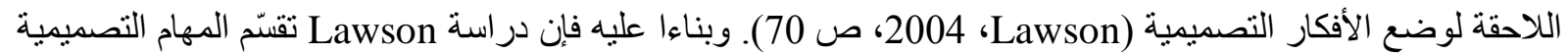
بين الرسوم اليدوية والرسوم الحاسوبية معتبرة أن الرسوم اليدوية هي الأكثر نجاحا في مر احل التصميم الأولية.

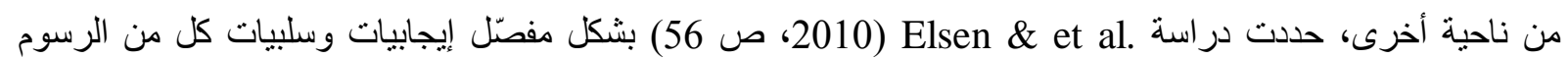

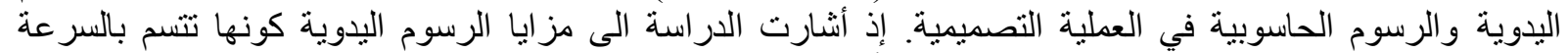

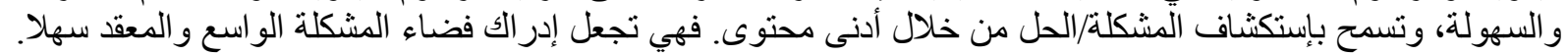

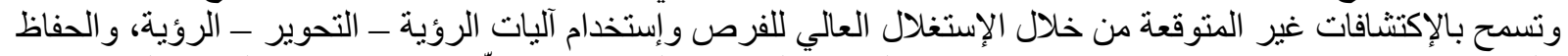

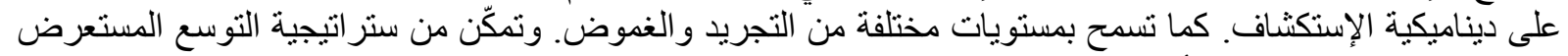

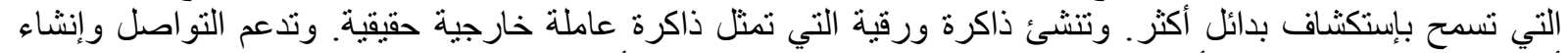

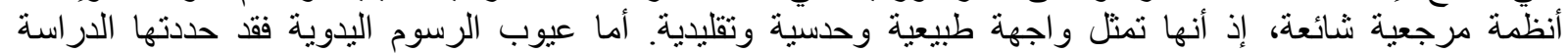

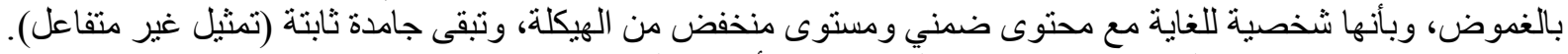

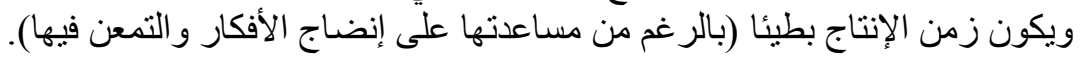

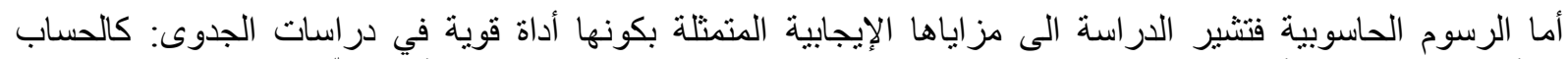

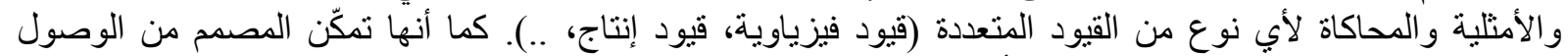

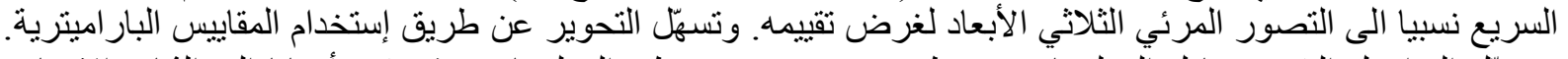

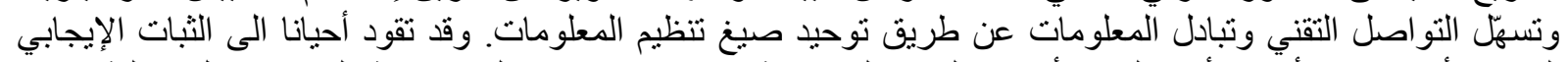

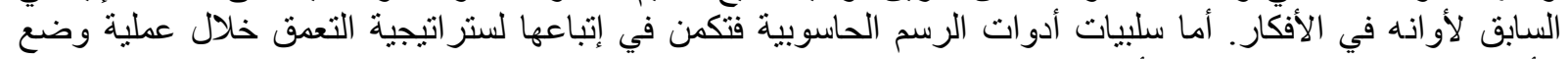

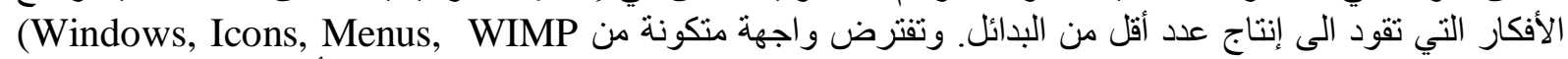

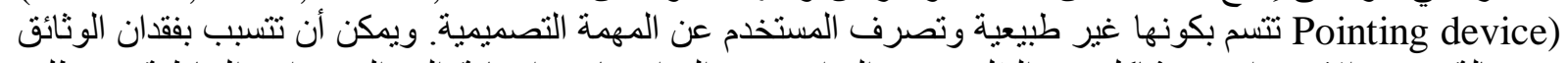

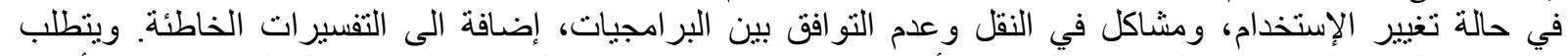

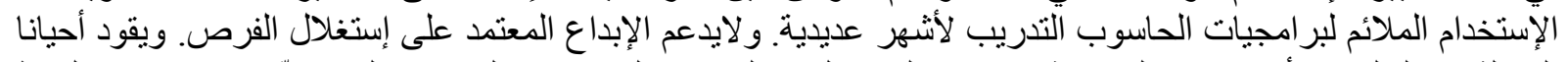

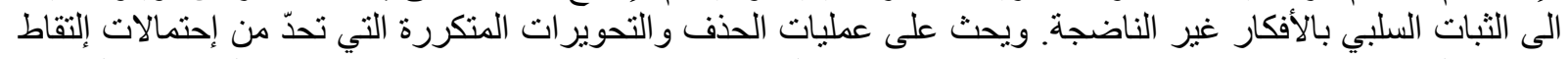

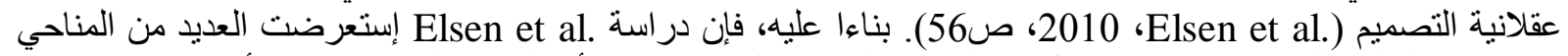

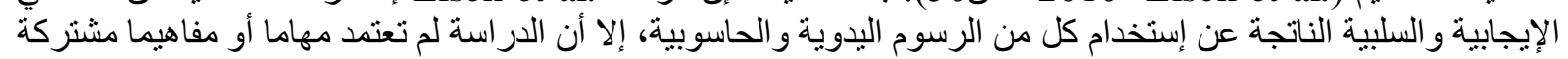

أساسا للمقارنة بينهما.

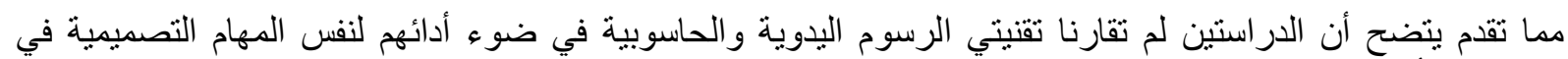

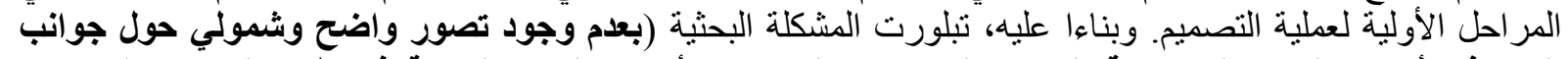

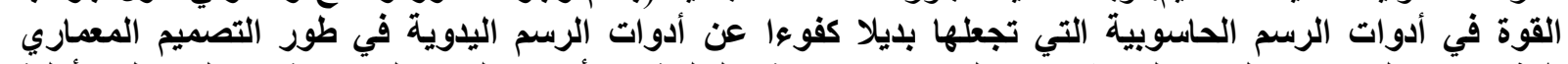

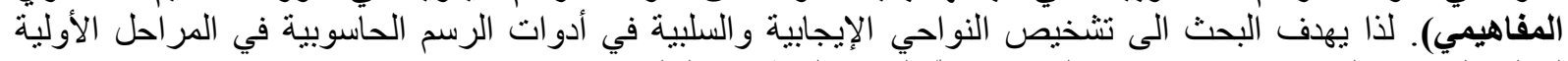

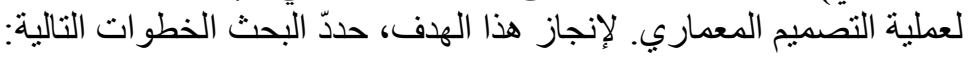

تحديد المهام التي تنجز ها الرسوم اليدوية التخطيطة في مر احل بناء الفكرة التصميمية.

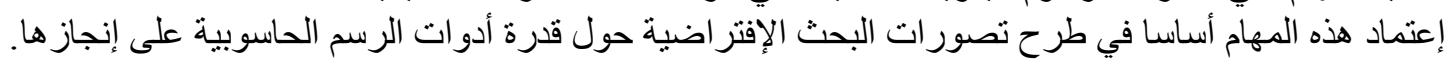

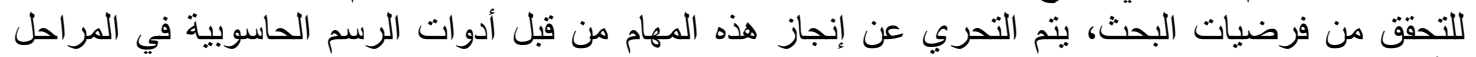

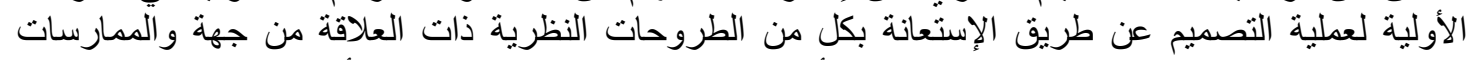

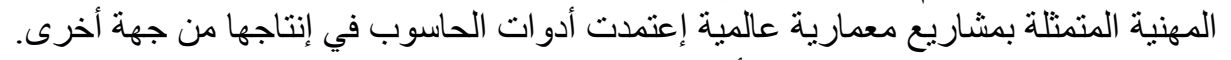

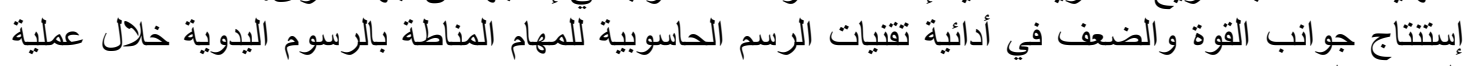
التصميم المفاهيمي.

يتناول البحث في فقرته التالية تعريفا بأدوار الرسوم اليدوية التخطيطية في المر احل البدئية لعملية التصميح. 3. مهام الرسوم اليدوية التخطيطية في مرحلة وضع الأفكار التصميمية المعمارية

تناولت العديد من الدراسات أهمية الرسوم التخطيطية اليدوية في مرحلة توليد الأفكار المعمارية وحددت أدوارها في مجمو عة من المهام. ومن هذه الدراسات: 


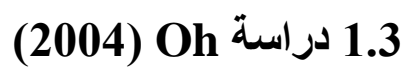

حددت دراسة Oh ثلاث أدوار أساسية للرسوم اليدوية التخطيطية في العملية التصميمية بوصفها أداة لإستخر اج أفكار

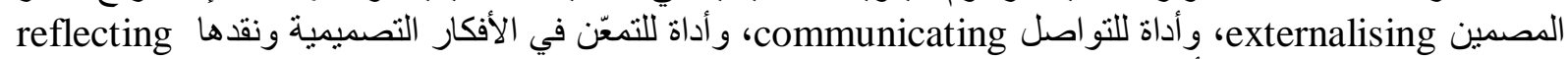
on design ideas

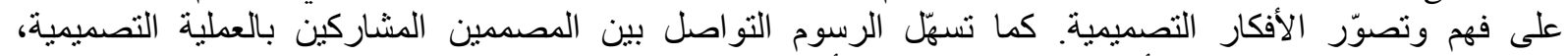

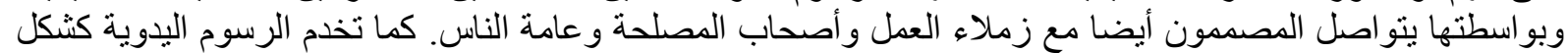

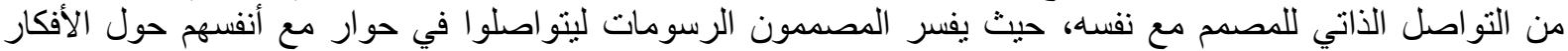

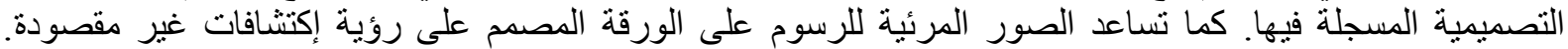

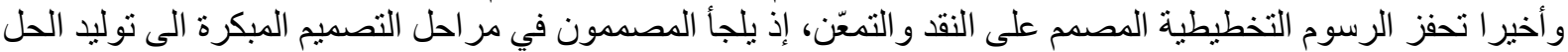

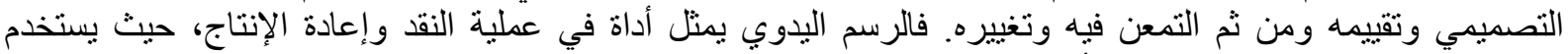

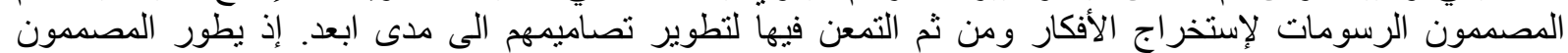

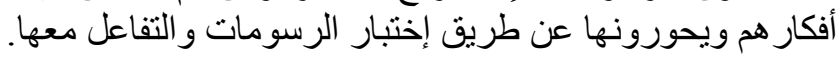

يتضح مما تقدم أن دراسة Oh (2004) عرفت ثلاث أدوار أساسية للرسوم اليدوية في مراحل التصميم الأولية وهي أداة

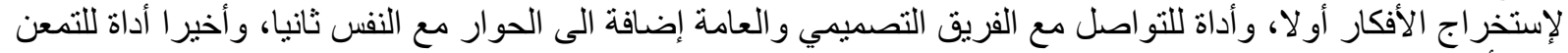

في الأفكار بهدف تطوير ها.

\section{(2004) Lawson 2.3 دراسة كرة}

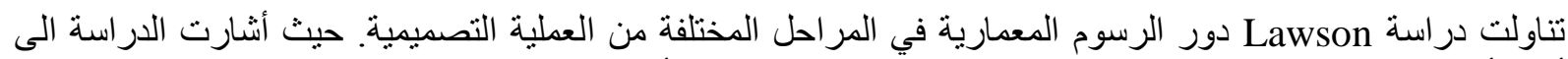

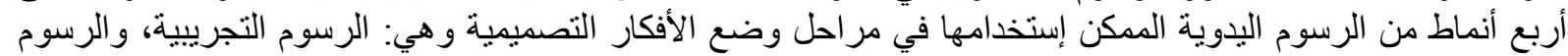
التوضيحية، و الرسوم الر ائعة، و الرسوم الإفتر اضية.

بالنسبة الى الرسوم التجريبية Experiential drawings، يشير Lawson الى أنها جزء حقبقي من البنية التحتية

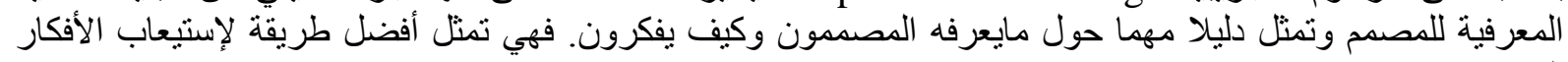

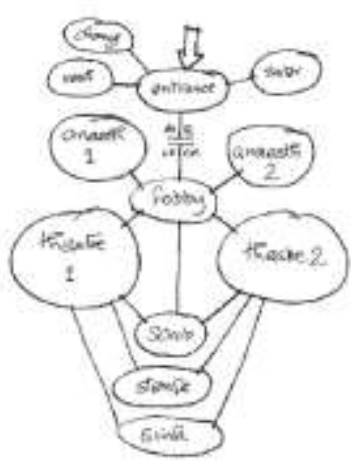

الثكل 1: الرسوم التوضيحية

(444: 2004، Lawson)

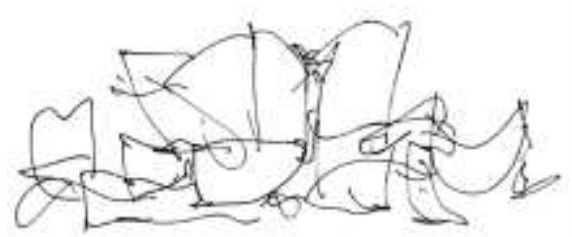

الشكل 2: رسم تخطيطي للمعماري Gehry

التصميمية (2004، صعتة صلمند).

ويطلق Lawson على الرسوم التوضيحية Diagrams برسوم التفكير التي

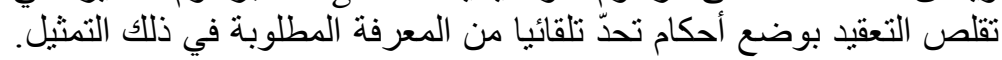

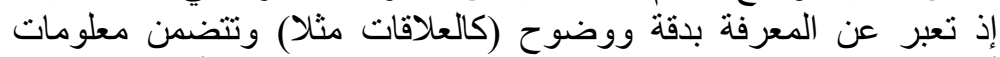

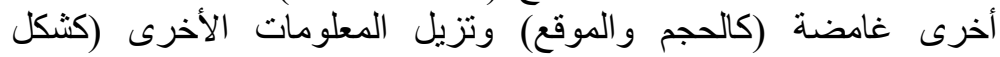

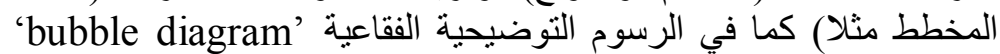

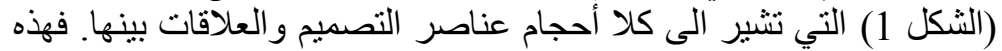

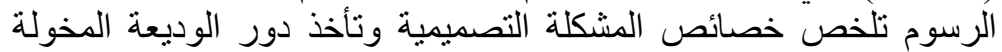

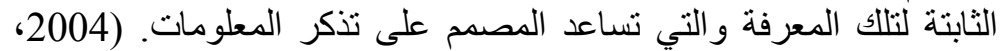

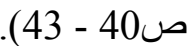

ويعرف Lawson الرسومات الرائعة Fabulous drawings بأنها

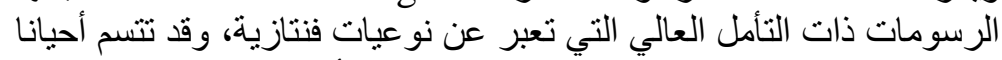

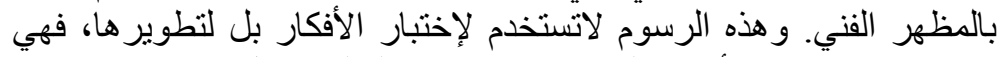

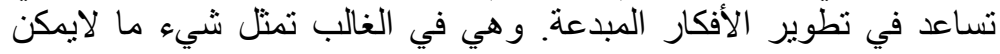

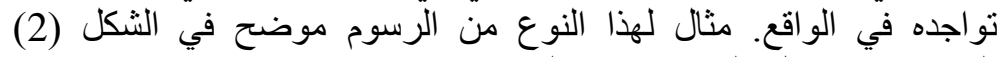

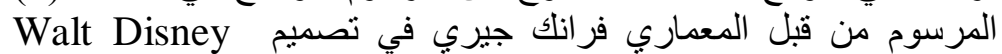
Concert Hall التصميم. (2004، صي443-43)

(444:Lawson)

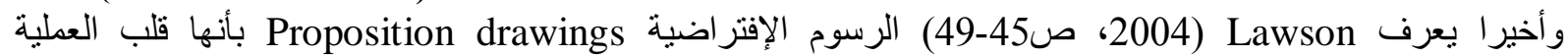

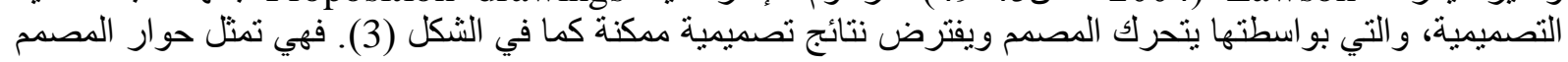




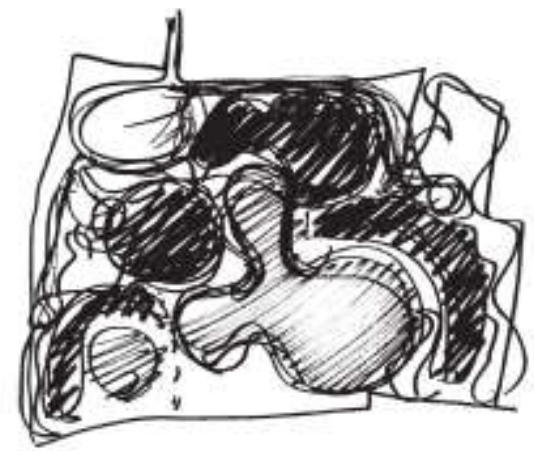

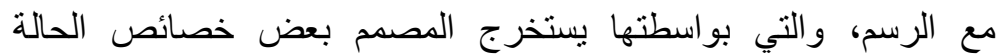

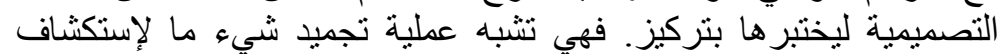

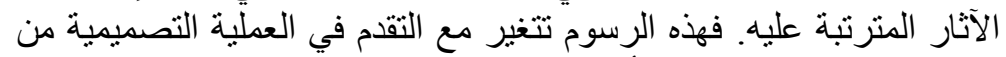

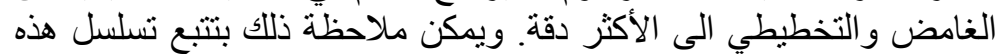

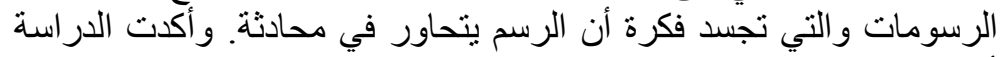

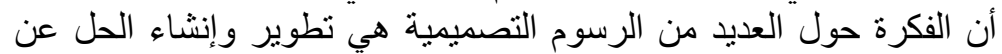

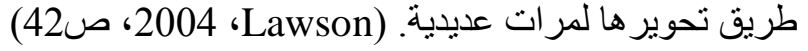

\section{الثكل (3): رسم إفتراضي للمعماري Lawson) Ken Yeang، 2004، (46)}

يتضح مما تقام أن تصنيف Lawson للرسوم الممكن إستخدامها في مرحلة وضع الأفكار التصميمية يتضمن عدة أنسام مهام

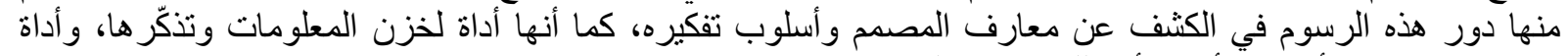

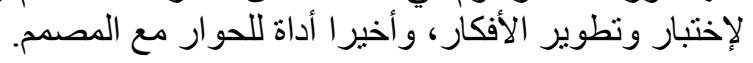

\section{(2008) (200) دراسة القزاز}

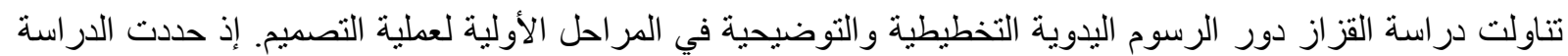

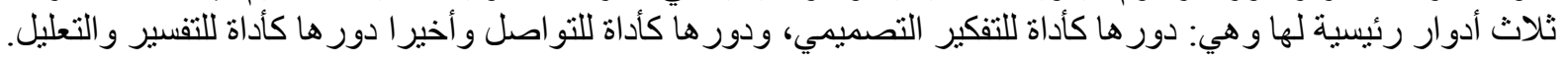

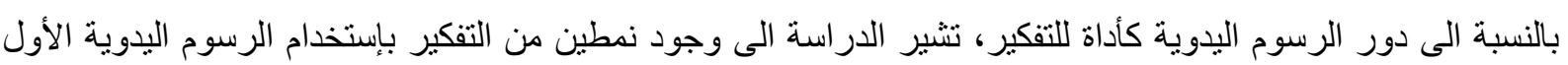

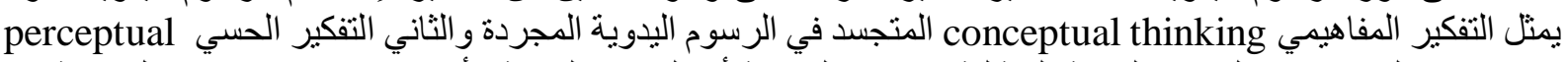

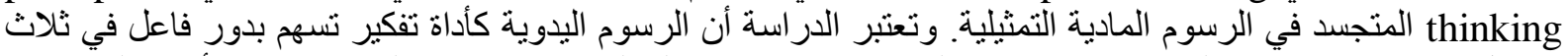

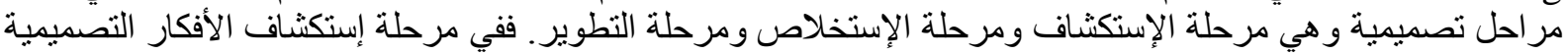

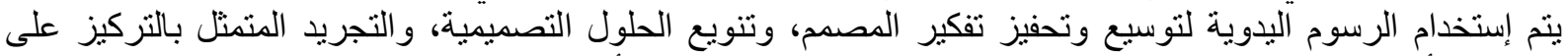

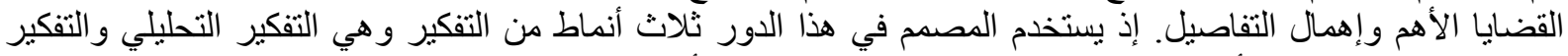

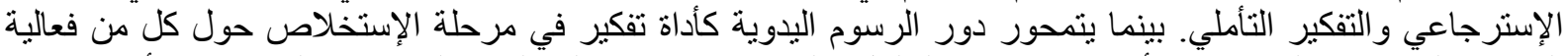

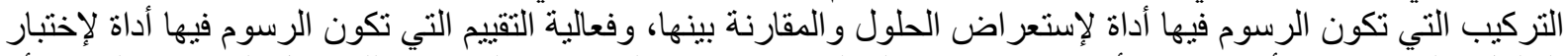

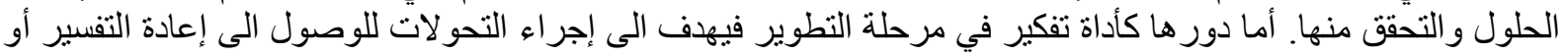
الى إكتشافات غير منوقعة.

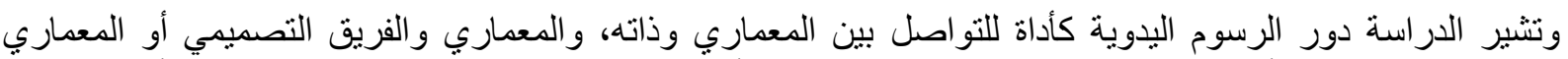

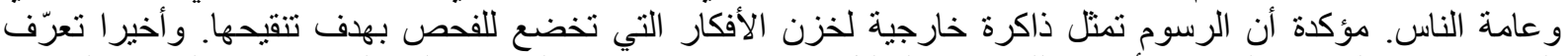

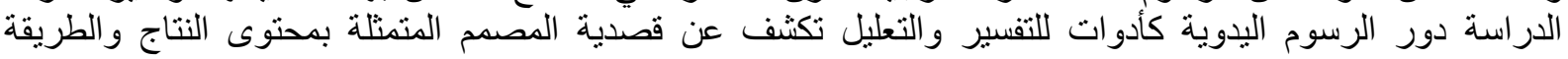

التصميمية المتبعة في الوصول الئور إليه.

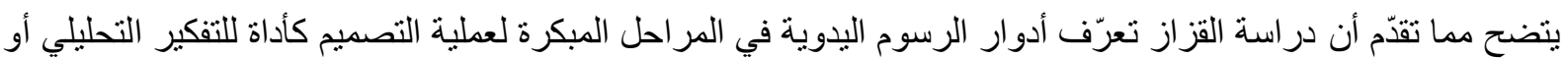

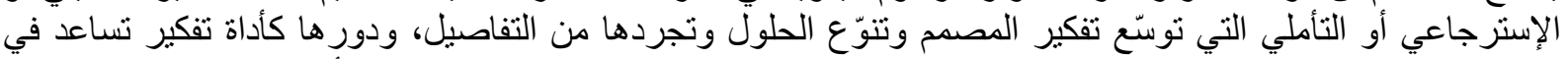

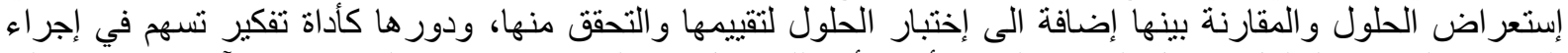

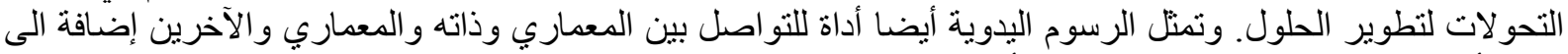

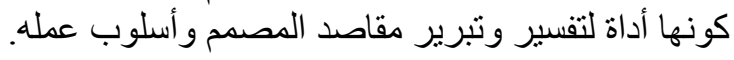

\section{(2009) Cook \& Agah 4.3}

أشارت دراسة Cook \& Agah الى أن الرسوم اليدوية بالقلم والورقة تتكون من ثلاث عناصر الأول منها يمثل المكون

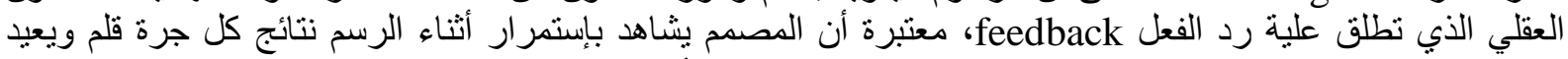

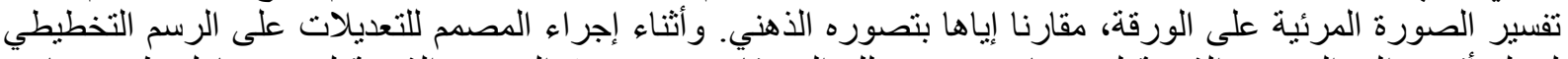

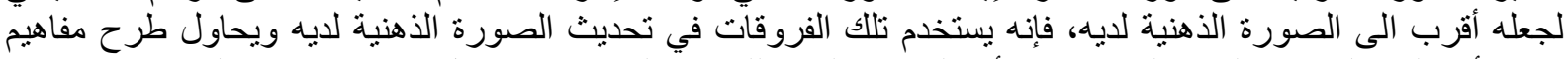

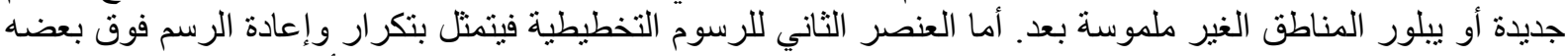

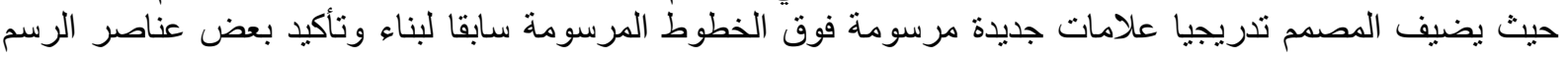




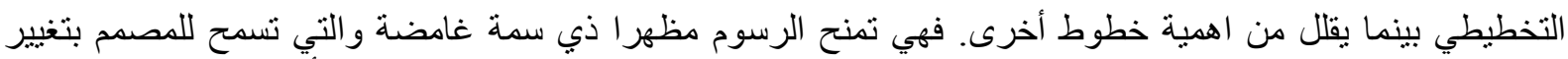

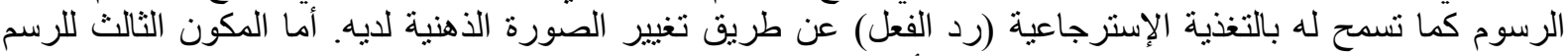

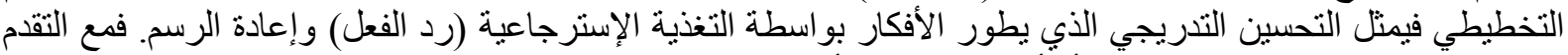

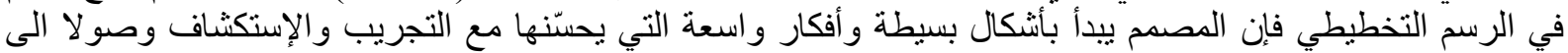

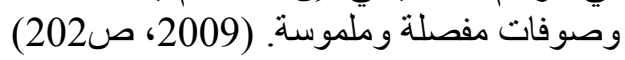

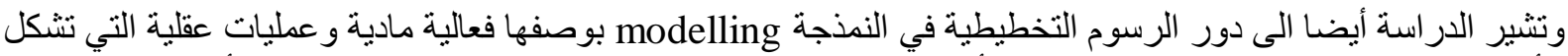

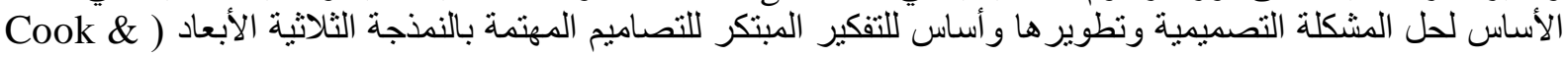
(203) Agah يتضح مما تقدم أن دراسة Cook \& Agah تعرف دور الرسوم اليدوية في عملية التفكير التصميمي إضافة دوره في عملية التجريب وعملية تحسين وتطوير الأفكار التصميمية.

\section{4. الخلاصة: مهام الرسوم اليدوية التخطيطية في مرحلة وضع الأفكار التصميمية المعمارية}

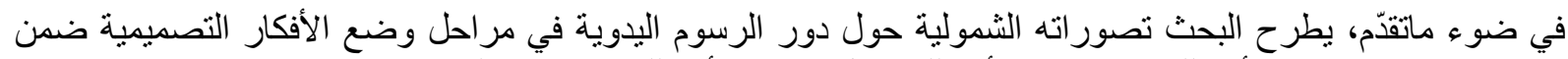

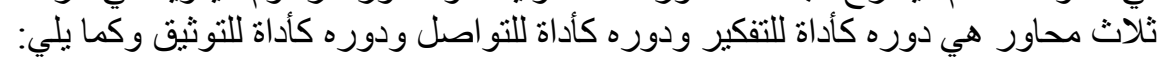

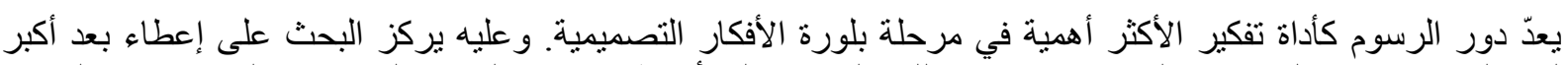

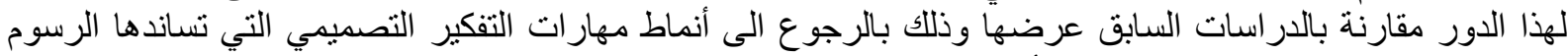

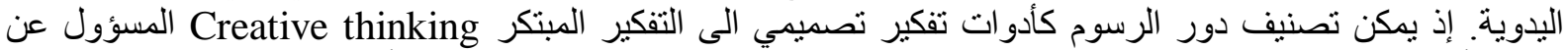
إنتاج الأفكار المبدعة، والتفكير التجريبي thinking Experimental المسؤول عن نقد الأفكار التصميمية وتطوير ها، إذ إذ النيا يتضمن كل منها أنماط التفكير الفرعية التنالية :

الرسوم اليدوية أداة للتفكير المبنكر Creative thinking: إذ تعد الرسوم اليدوية التخطبطية أداة مساعدة في

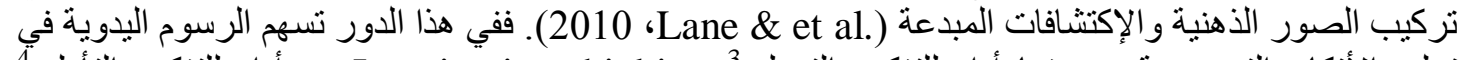

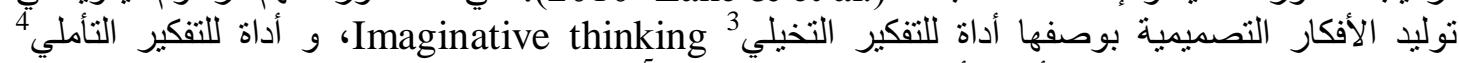
Retrospective thinking 5 Introspective thinking

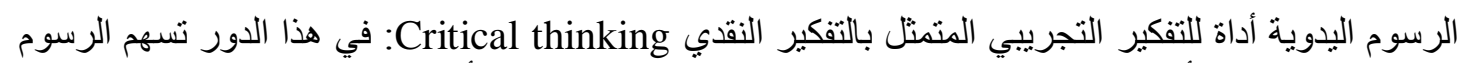

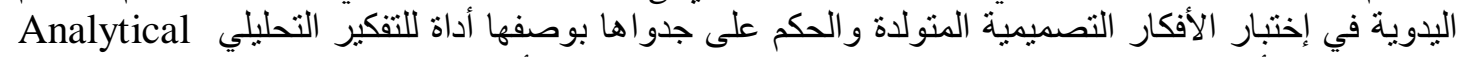

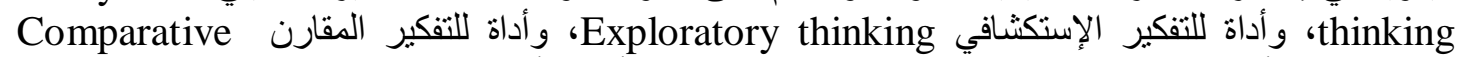

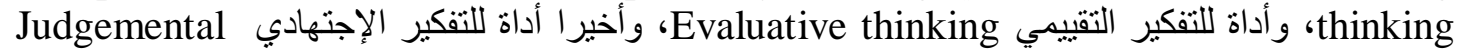
.thinking

الرسوم اليدوية أداة للتفكير التجريبي المتمثل بالتفكير التطويري Developmental thinking: في هذا الدور

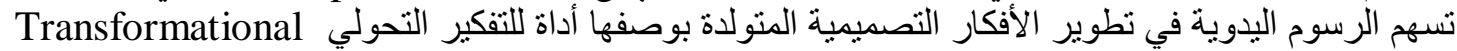

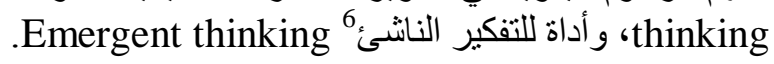
كما يعرف البحث دور الرسوم التخطيطة كأداة للتواصل تتمحور حول جانبي مفهوم التواصل وهما: تبادل المعلومات

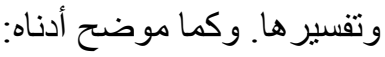

الرسوم التخطيطية أداة لنقل الأفكار من المصمم الى الفريق التصميمي أو من المصمم الى الى العامة.

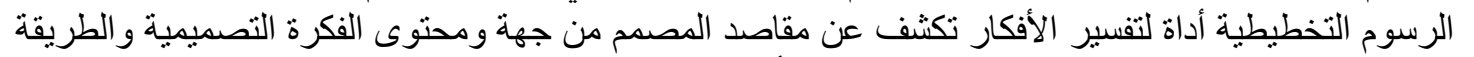

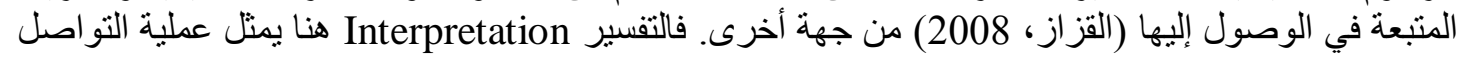
التي تكثف عن المعنى الدلالي و التركيبي للتصميم. فالتواصل التفسيري لايمثل فقط عرضا للمعلومات ولكنه

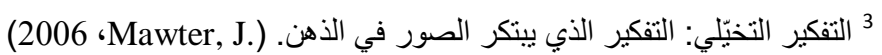

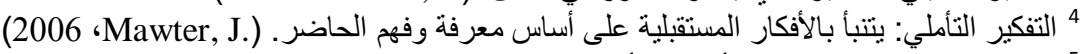

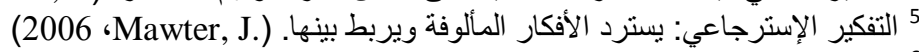
6 التنكير النانثيء أو الطاريء: بستقريء ألفكار جديدة من بين الأفكار الموجودة، وينتج غالبا عن الغوض الفوض المتأصل في الرسوم اليدوية. 


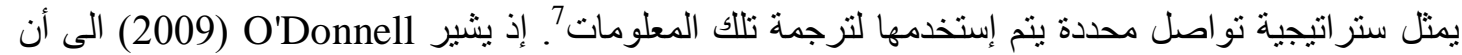

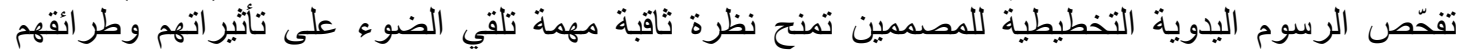
ووجهات نظر هم نحو العالم. فالرسوم تمثل طريقة ممتازة لتعزيز فهمنا حول ما يعرفه المصممون (Lawson)،

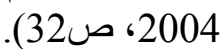

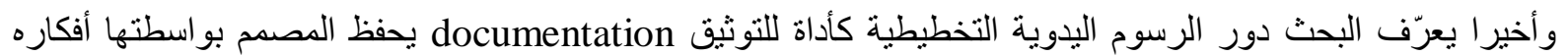

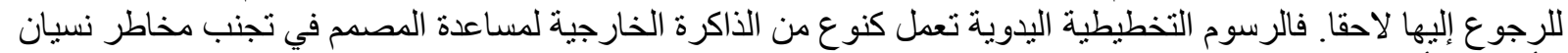

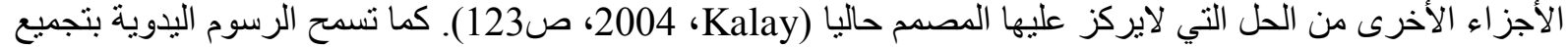

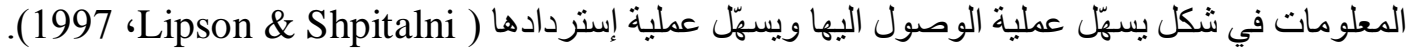
يوضح الجدول (1) أدوار الرسوم اليدوية في المر احل الأولية لعملية التصميم المعماري. جدول 1: دور الرسوم اليدوية في مرحلة وضع الأفكار التصميمية (المصدر: الباحث)

\begin{tabular}{|c|c|c|c|}
\hline أداة للتفكير التخيلي & \multirow{3}{*}{\multicolumn{2}{|c|}{ الرسوم اليدوية أداة للتفكير المبتكر }} & \multirow{10}{*}{ أل أداة للتفكير اليدوية } \\
\hline أداة للتفكير التأملي & & & \\
\hline أداة للتفكير الإسنرجاعي & & & \\
\hline أداة للتفكير التحليلي & \multirow{5}{*}{ 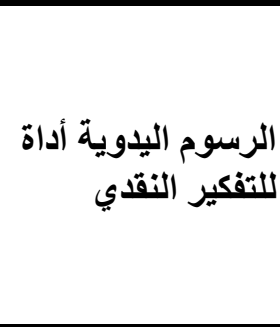 } & \multirow{7}{*}{ للتفكير التجريبي اليدوية أداة } & \\
\hline أداة للتفكير الإستكشافي & & & \\
\hline أداة للتفكير المقارن & & & \\
\hline أداة للتفكير التقبيمي & & & \\
\hline أداة للتفكير الإجتهادي & & & \\
\hline أداة للتفكير التحولي & \multirow{2}{*}{ للتفكير التطويرية الديدية } & & \\
\hline أداة للتفكير الناشىء & & & \\
\hline نقل الأفكار من المصمم الى الفريق & \multirow{2}{*}{\multicolumn{2}{|c|}{ الرسوم اليدوية أداة لنقل الأفكار }} & \multirow{5}{*}{ أداة للتوماصل اليدوية } \\
\hline نقل الأفكار من المصمم الى العامة & & & \\
\hline تفسير مقاصد المصمم & \multirow{3}{*}{\multicolumn{2}{|c|}{ الرسوم اليدوية أداة لتفسير الأفكار }} & \\
\hline تفسير محتوى التصميم & & & \\
\hline تفسير طريقة التصميم & & & \\
\hline & \multicolumn{2}{|c|}{ تحفظ الأفكار في الرسومات للرجوع إليها لاحق } & أداة للتومثيقي اليذوية \\
\hline
\end{tabular}

5. فرضيات البحث - إيجابيات وسلبيات أدوات الرسم الحاسوبية في مراحل التصميم المفاهيمية تتمحور فرضيات البحث حول المهام الثثلاث التي تتجز ها الرسوم اليدوية والتي نم إستقر اؤها في الفقرة السابقة. فبالنسبة الى لى دور الرسوم الحاسوبية كأداة للتفكير يضع البحث الفرام الفرضيات التالية: لاتعزز أدوات الرسم الحاسوبية مهار ات التفكير المبتكر بأنو اعه: التخيلي والتأملي والإسترجاعي. 
تسهم أدوات الرسم الحاسوبي بشكل فاعل في مهارات التفكير التجريبي النقدي وبشكل خاص التفكير التحليلي و الإستكثافي و المقارن و التقييمي. تسهم أدو ات الرسم الحاسوبي بشكل فاعل في مهارات التفكير التجريبي النقدي وبشكل خاص التفكير التحولي. بالنسبة الى دور الرسوم الحاسوبية كأدوات للتواصل، يضع البحث الفرضيات التالية: تسهم أدوات الرسم الحاسوبي بشكل فاعل في تبادل المعلومات بين المصمم وفريقه و المصمم و العامة.

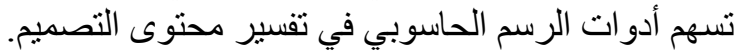
تفتقر أدو ات الرسم الحاسوبي الىى القدرة على تفسير مقاصد المصمح و الطريقة المتبعة في التصميم.

بالنسبة الى دور الرسوم الحاسوبية كأدوات للتوثيق، يضع البحث الفرضية التالية: تسهم أدوات الرسم الحاسوبي بشكل فاعل في حفظ الأفكار في الرسوم للرجو علئ إليها لاحقا من قبل المصدم.

\section{6. أدائية أدوات الرسم الحاسوبية في مرحلة وضع الأفكار التصميمية المعمارية} للتحقق من فرضيات البحث، نمّ إعتماد الطروحات النظرية الى جانب الممارسات المهنية في التحري عن كفاءة أدوات

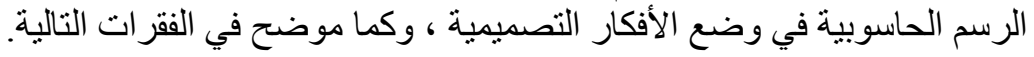

\section{6 الطروحات النظرية حول إستخدام الرسوم الحاسوبية في مرحلة التصميم المفاهيمي}

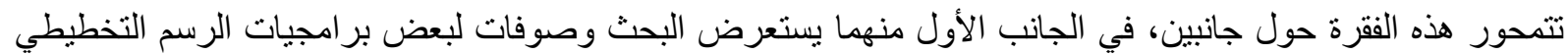

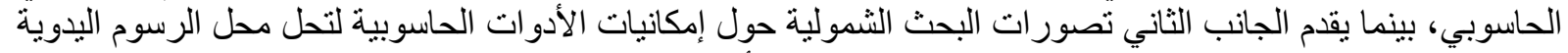

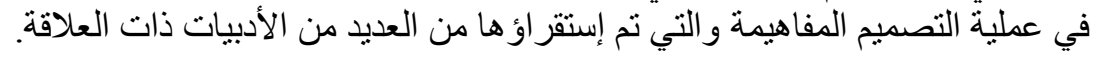

1.1.6 إستعراض برمجيات الرسم الحاسوبية

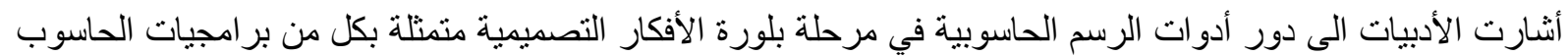

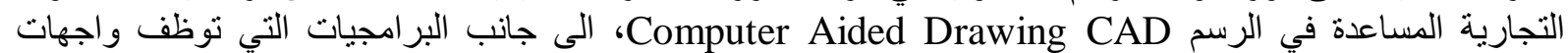
المستخدم للرسم التخطيطي

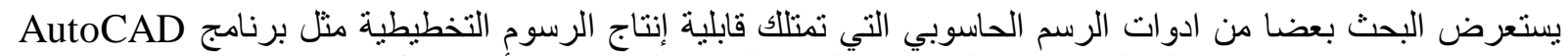

وبرنامج SketchUp إضافة الى البر امجيات التي تعتمد الرسم البدوي التخطبطي كأداة إدخال Sketch-based CAD.

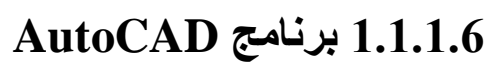

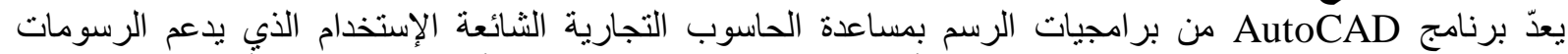

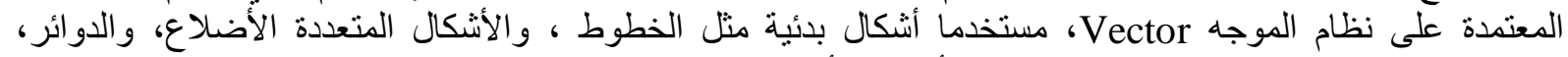

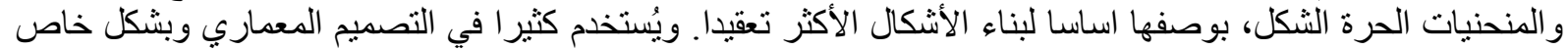

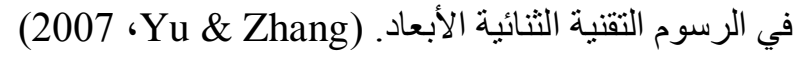

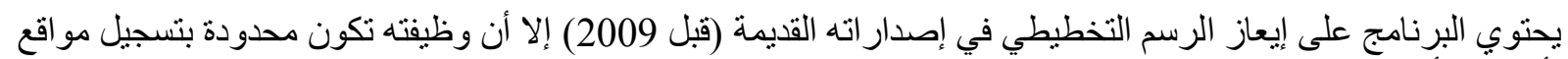

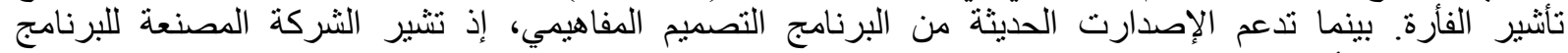
Autodesk

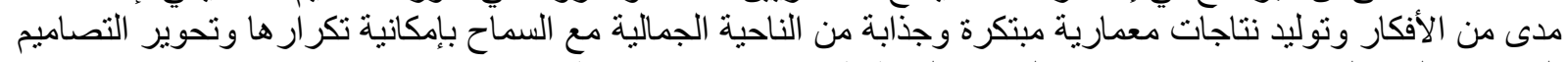

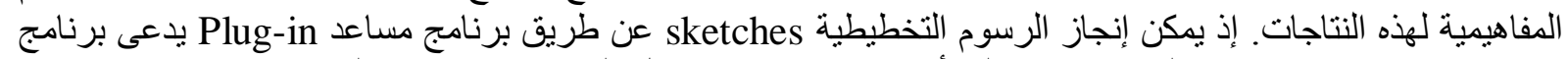

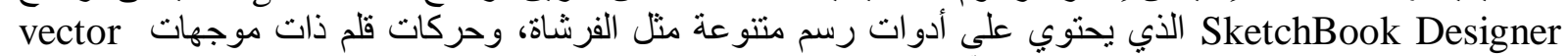
strokes

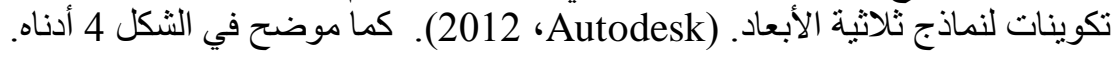




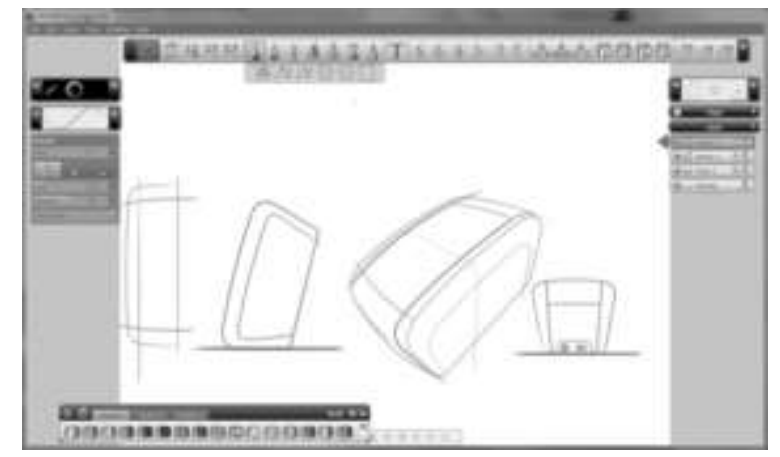

الثكل 4: واجهة المستخدم لبرنامج SketchBook Designer (المصدر: الإنترنيتج)

كما يحتوي برنامج AutoCAD نفسه على إمكانيات التصميم المفاهيمي مثل نمذجة الثبكة، ونمذجة الأسطح، ونمذجة

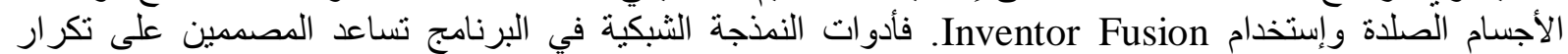

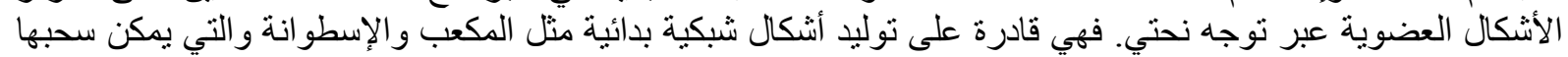

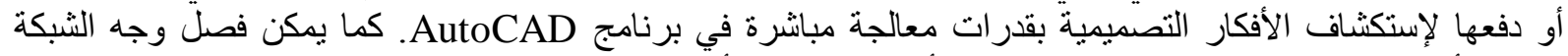

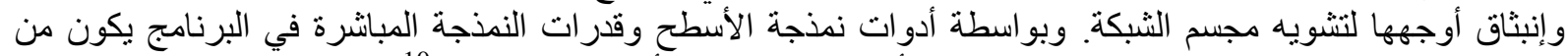

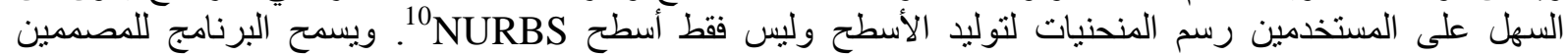

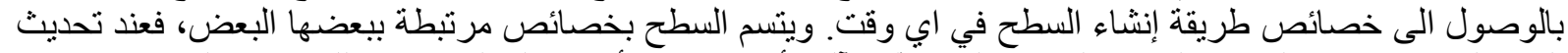

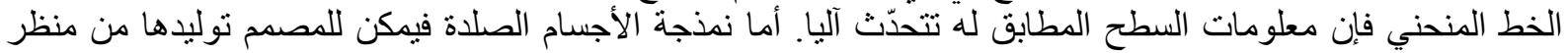

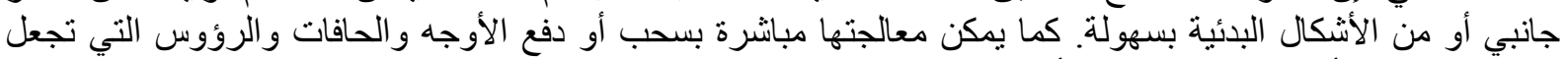
العمل في بيئة الأوتوكاد سهلة جدا. وأخيرا يضع Inventor Fusion مقاييس جديدة لسهولة السئة إستخدام النمذجة الثناثية

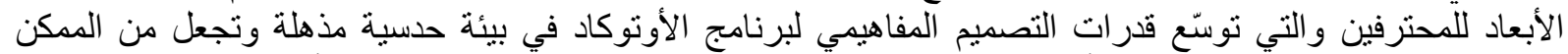

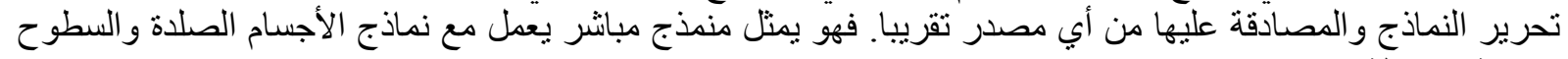

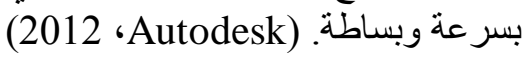

\section{SketchUp 2.1.1.6 برنامج}

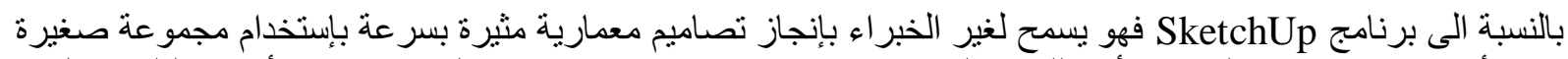

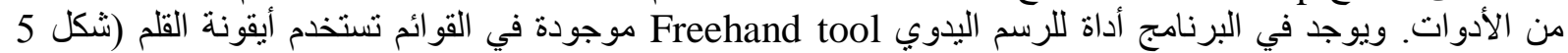

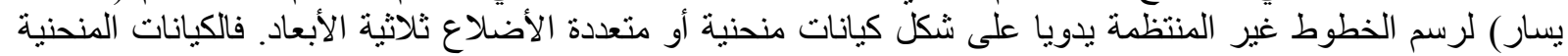

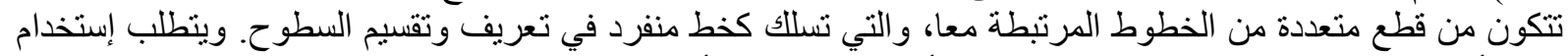

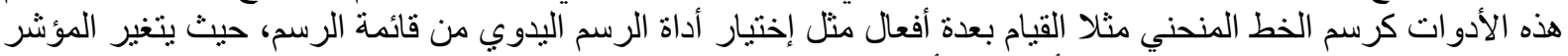

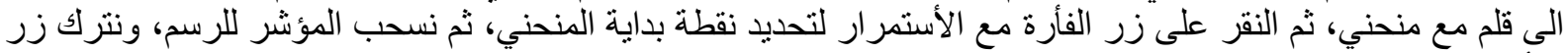

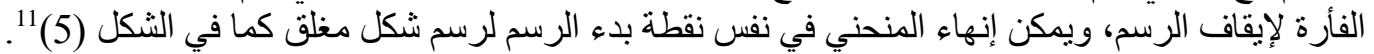
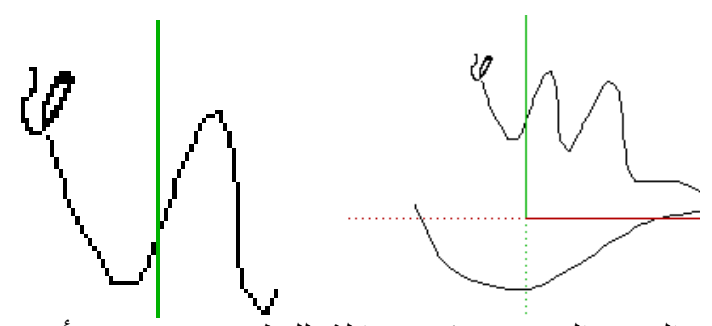

$$
\text { الشكل (5): الرسم اليدوي للمنحني في برنامج }
$$

ويمكن إستخدام أدوات الدفع والسحب موحدة مع أداة الرسم اليدوي وتكون قابلة للتطبيق في رسم أب سطح، وتمكّن

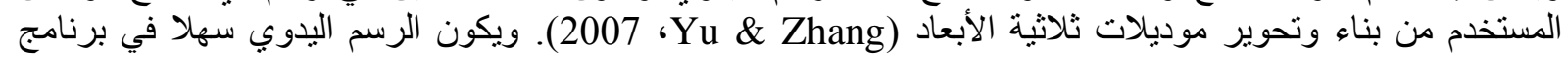

\footnotetext{
http://s3files.core77.com/blog/images/2011/07/image sketchbook 900.png ${ }^{9}$

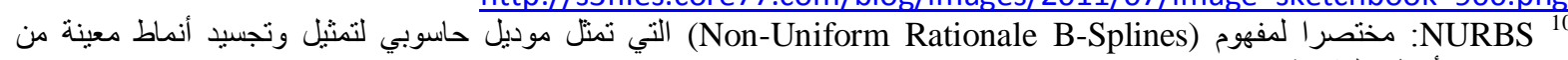


SketchUp

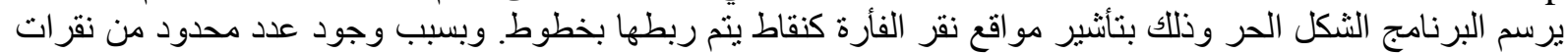

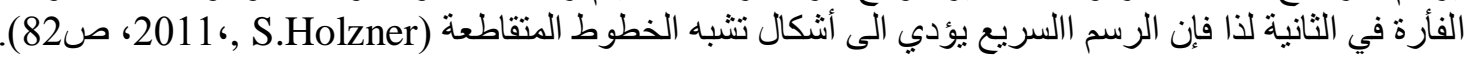

\section{Sketch-based interface 3.1.1.6 البرامج ذات واجهة مستخدم معتمدة على الرسم التخطيطي}

الفكرة الأساسية وراء و اجهات المستخدم المعتمدة على الرسم التخطيطي هي محاكاة القلم والورقة اللتين تمثنان الأسلوب

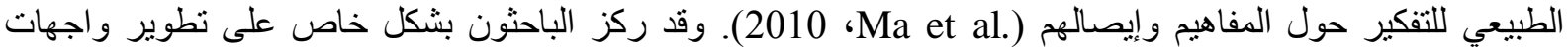

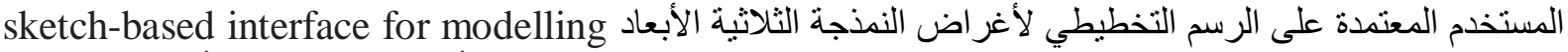

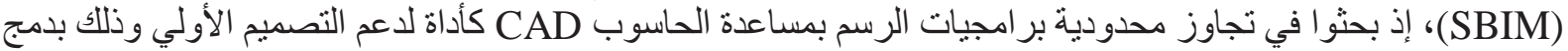

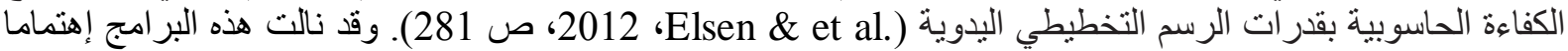

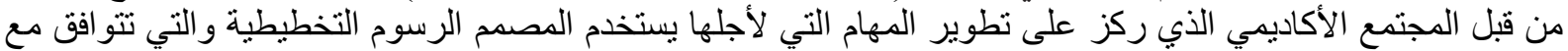

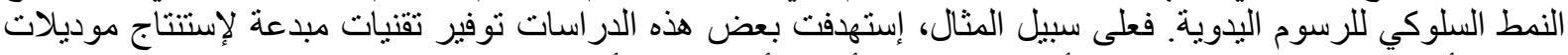

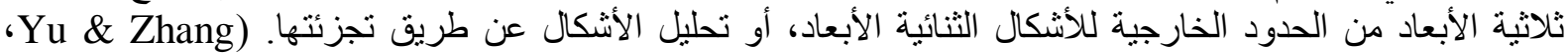

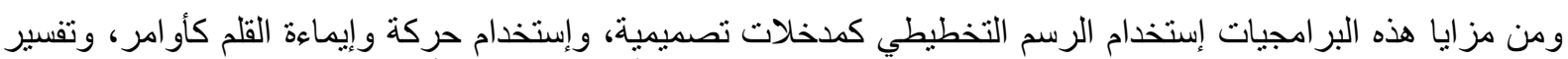

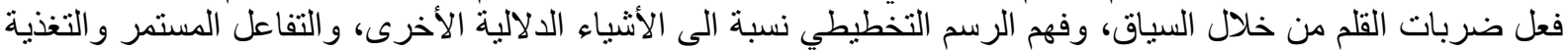

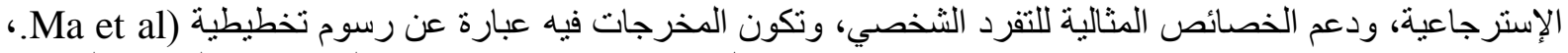

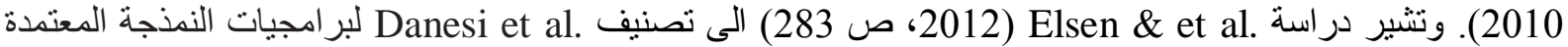

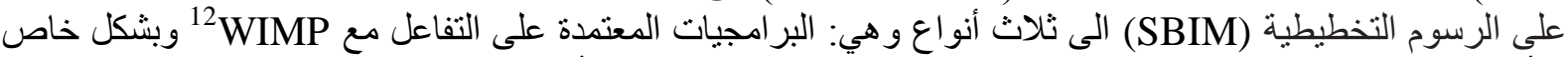

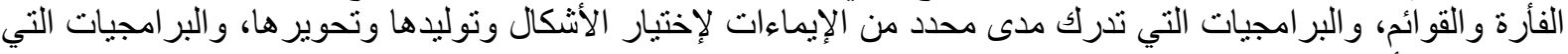

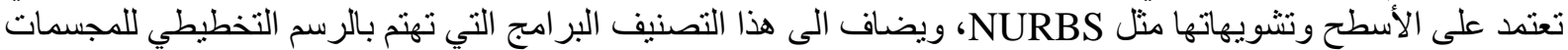

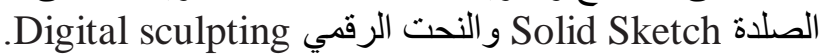

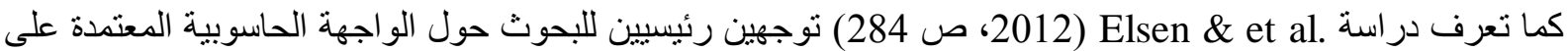

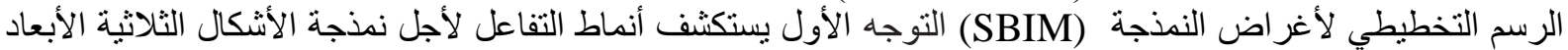

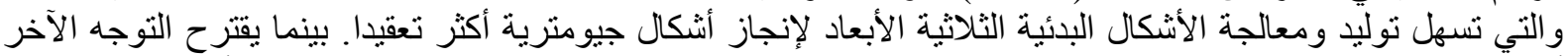

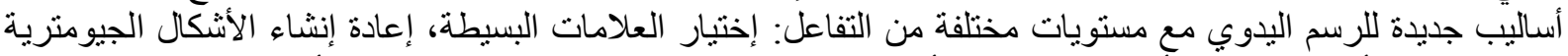

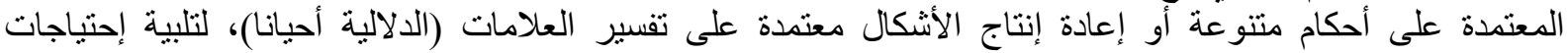
المصممين الذين يفضلون التفاعل وفقا لطر از القلم و الورقة.

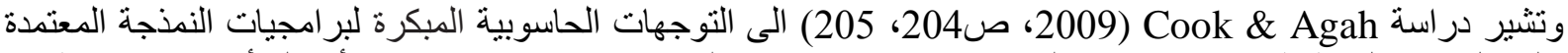

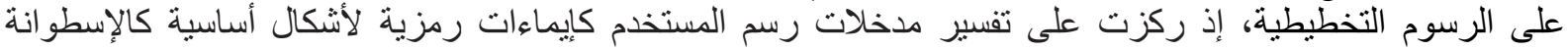

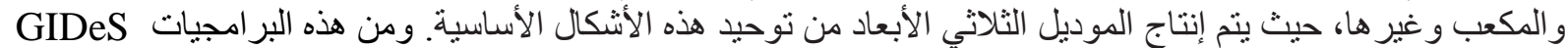
modeling prototype

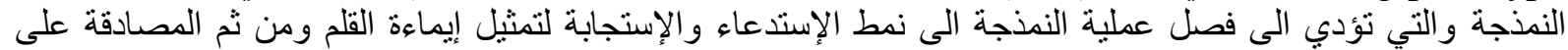

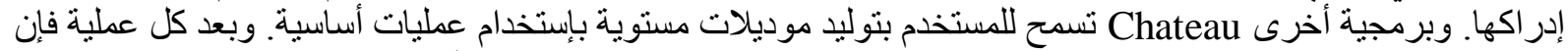

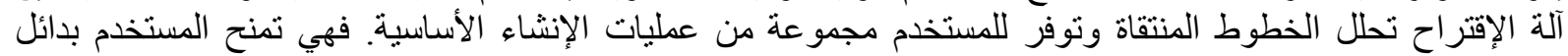
للحوار يتم تمثيلها في الجزء التمط السفلي من الثنانشة. في الفقرة التالية، يستعرض البحث إيجابيات وسلبيات أدوات الرسم الحاسوبية في المر احل الأولية لعملية التصميم. 2.6 دور أدوات الرسم الحاسوبية في مرحلة التصميم المفاهيمي

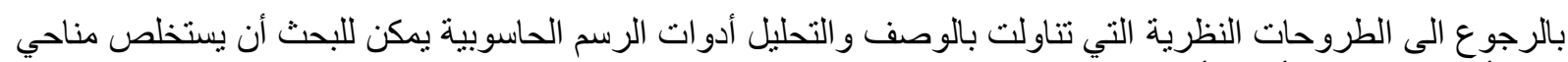

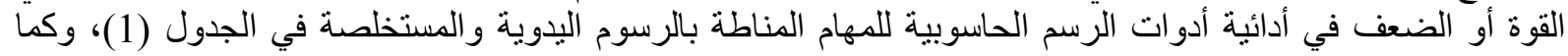
موضح في الفقرات التالية. 


\subsection{6 دور الرسوم الحاسوبية كأدوات للتفكير المبتكر}

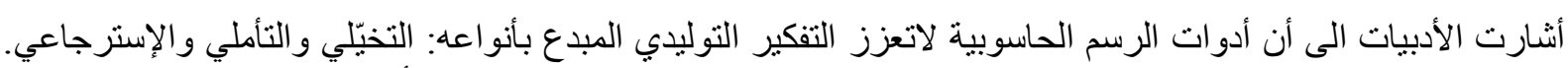

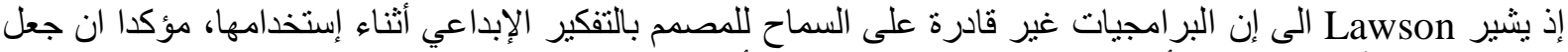

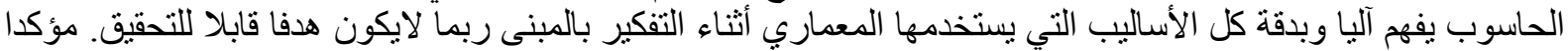

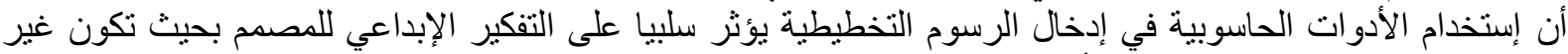

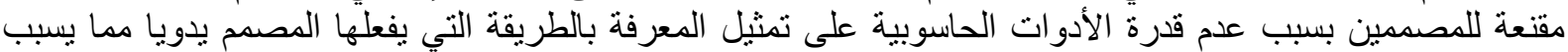

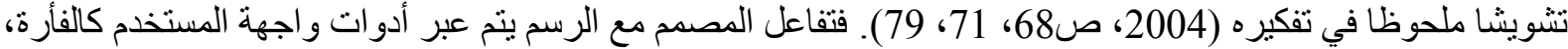

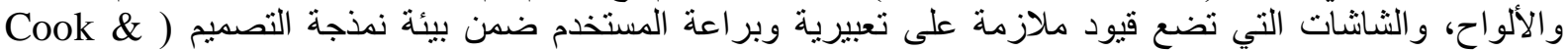
(210)، Agah

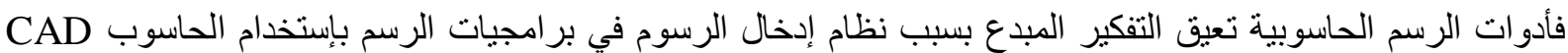

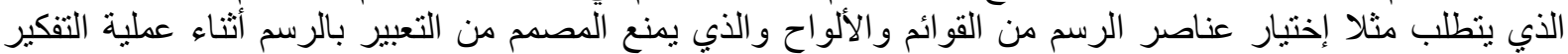
(Do \& Gross)

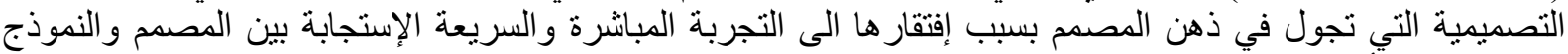

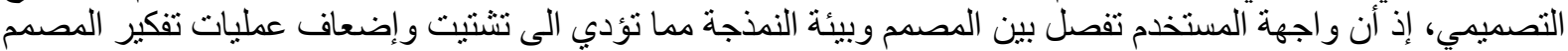
(Cook \& Agah)

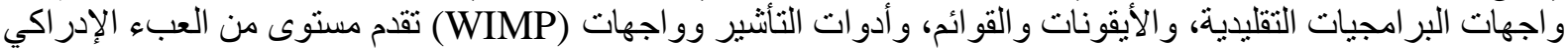

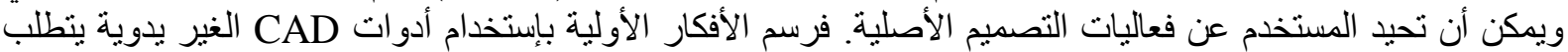

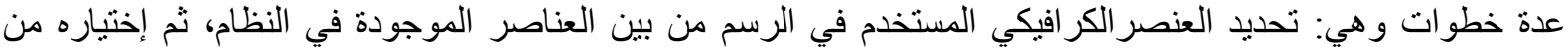

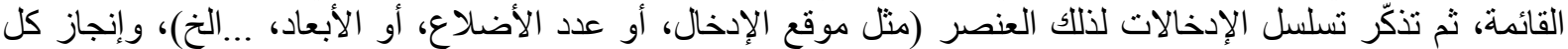

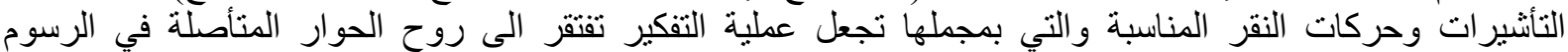

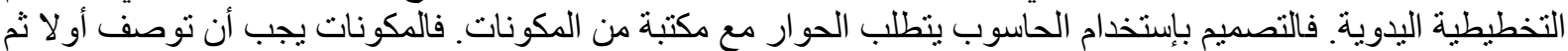

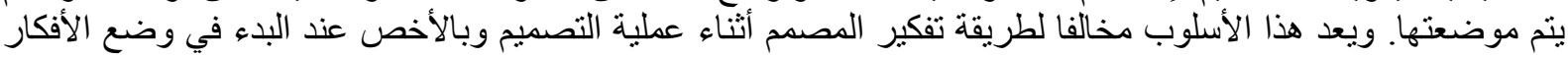

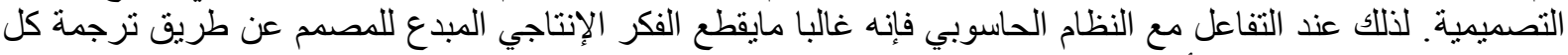

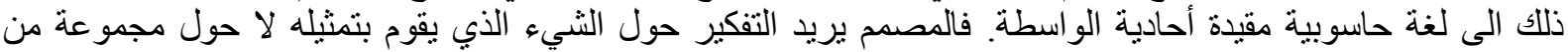

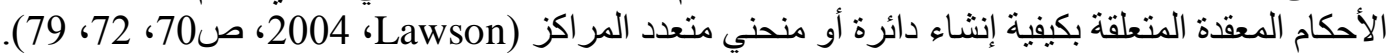

وتثير الدراسات الى بعض خصائص الرسم الحاسوبي التي تعيق التفكير المبدع للمصدم، ومنها الفصل الفيزياوي بين أداة

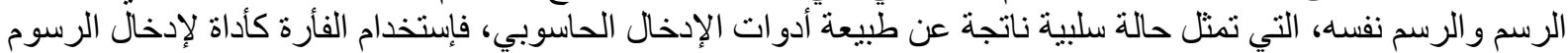

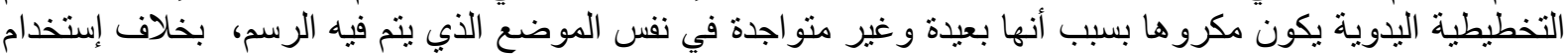

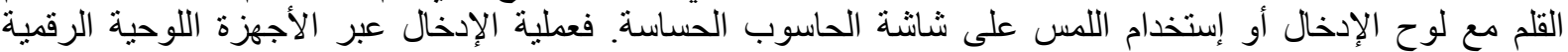

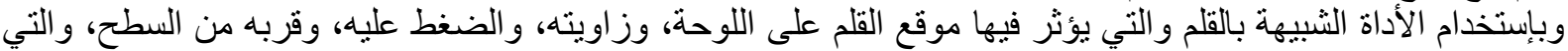

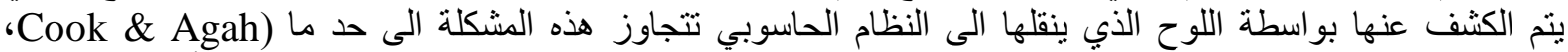

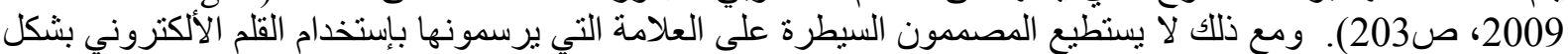

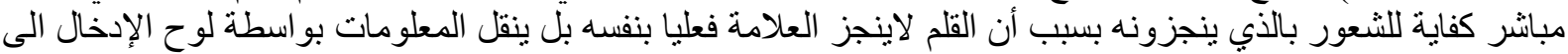

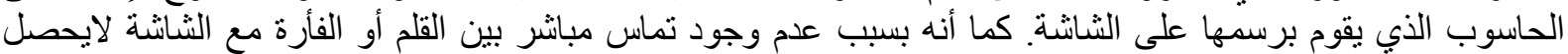

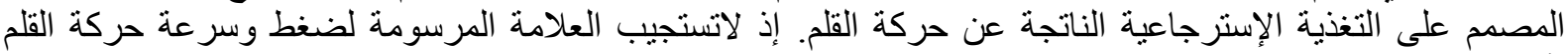

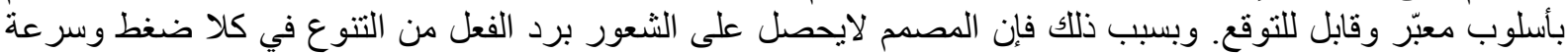

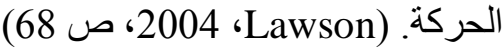

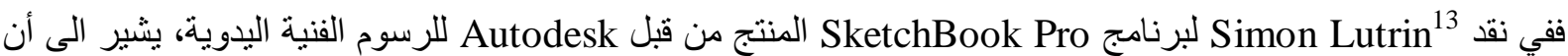

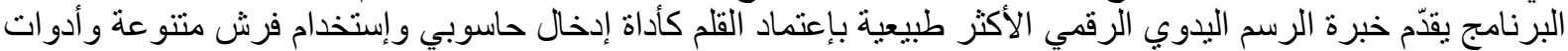

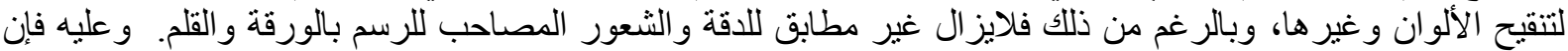
تحسين دور الرسوم الحاسوبية كأدوات للتفكير النقدي يتطلب تحسين التفاعل بين الإنسان والحاسوب للإبي في واجهة المستخدم 
المعتمدة على الرسم التخطبطي Sketch-based interface و التي تستلزم تحسين تقنيتين أساسيتين وهما تمثيل الرسم التخطيطي وفهم الرسم التخطيطي (Ma et al.

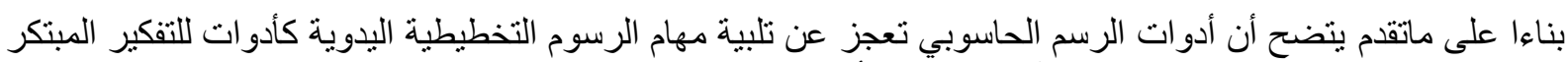

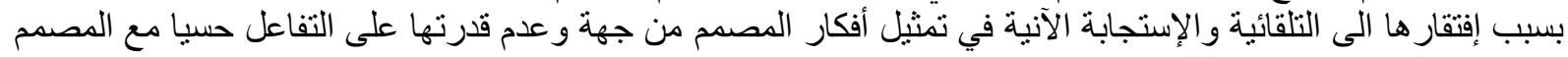
بالإستجابة لضغط وسر عة القلم مثلا.

\subsection{6 دور الرسوم الحاسوبية كأدوات للتفكير النقدي}

يشير Lawson الى أن الحاسوب يساعد المصممين في نمذجة خصائص تصميمية أكثر وإختبار ها بعمق تفكير أكبر.

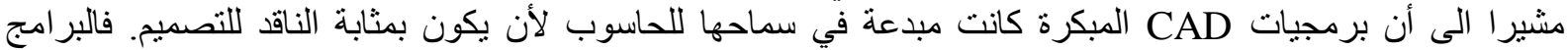

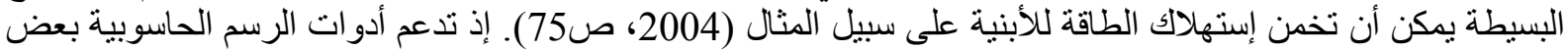

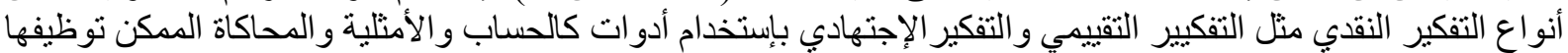

في نقد التصاميم الأُولية (. Elsen et al الفكير الفير 2010، ص 56).

ويشير الباحثان Yu \& Zhang (2007) الى أداة الرسم الحاسوبي المطورة من قبلهم التي تمكّن المعماري من الرسم

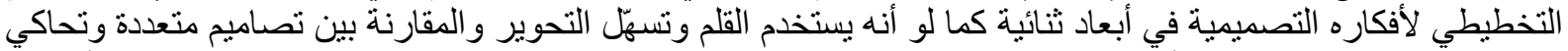

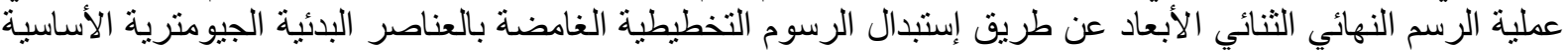

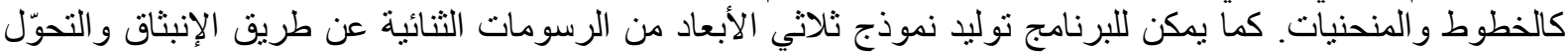

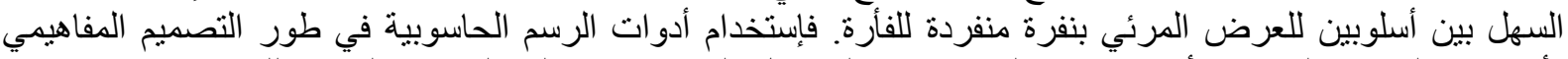

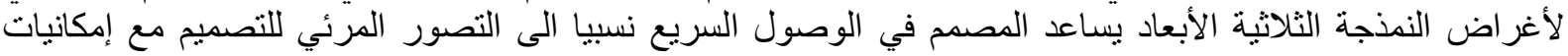

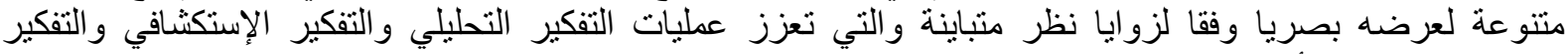

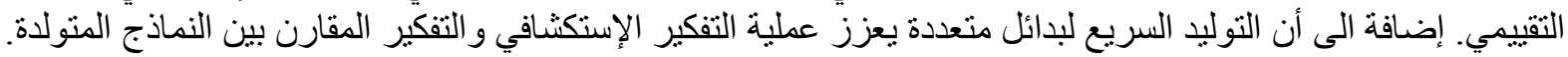

ومن ناحية أخرى، فإن فصل أدوات الرسم الحاسوبي عن أدوات التنقيح تمثل عقبة أمام المصمم. فعلى سبيل المنال عند

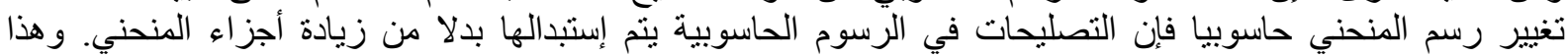

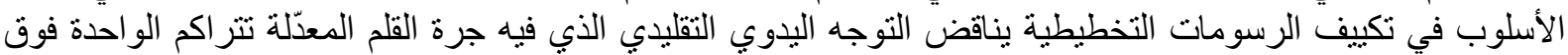

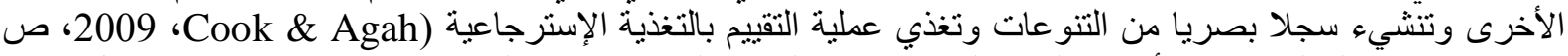
203). ففي هذه الحالة لاتساعد أدوات الرسم الحاسوبية في التفكير المقارن بإيجاد التماثلات والإنة الإختلافات بين مر احل نطور

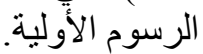

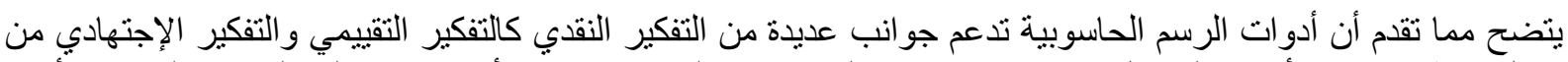

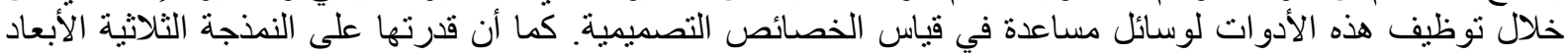

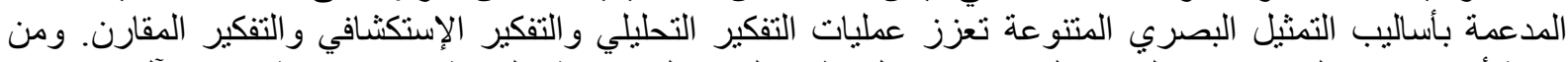

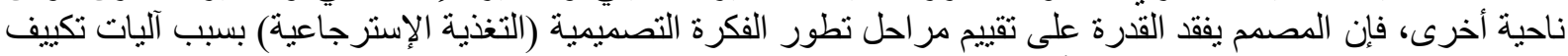
الرسوم الحاسوبية التي تستبدل الرسوم أثناء تنقيحها.

\subsection{6 دور الرسوم الحاسوبية كأدوات للتفكير التطويري}

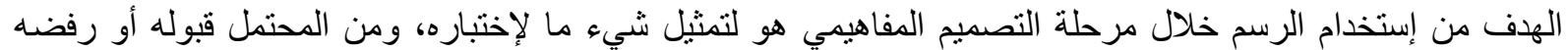

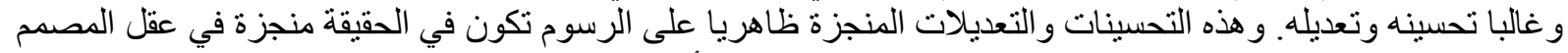

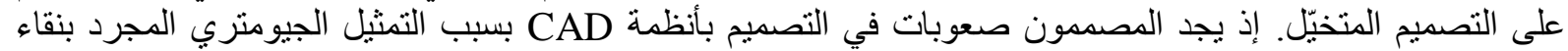

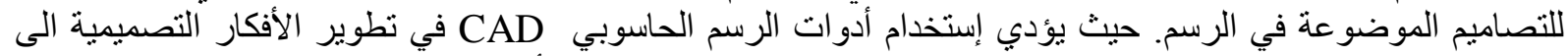

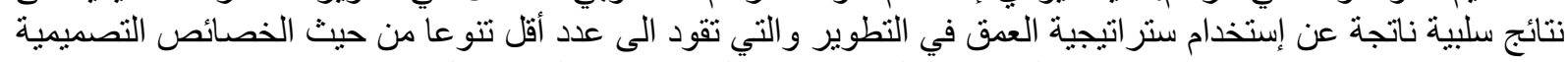
Elsen et.al)

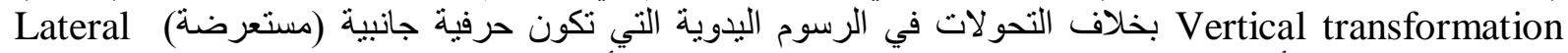
رransformation

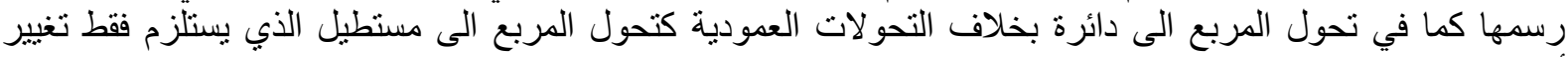




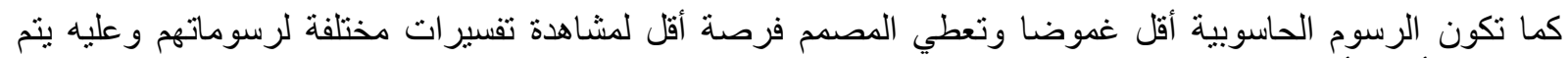

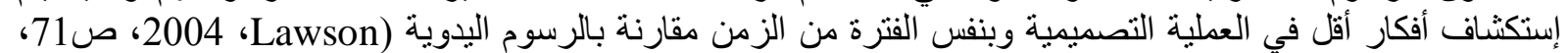

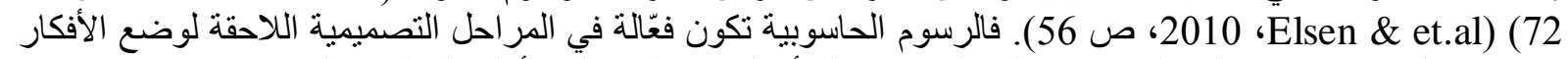

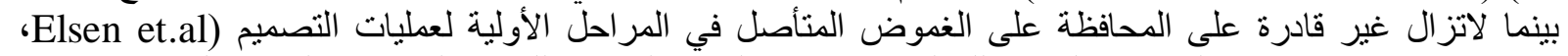

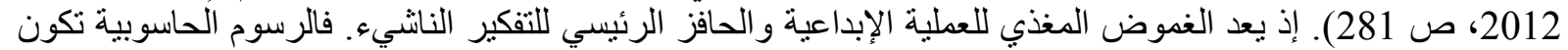

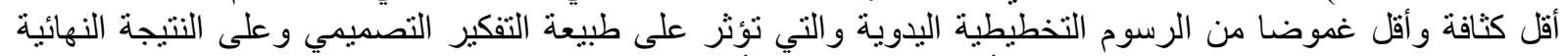

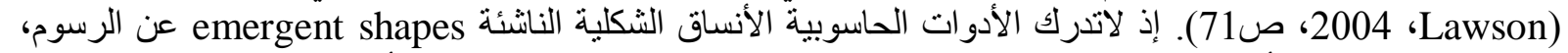

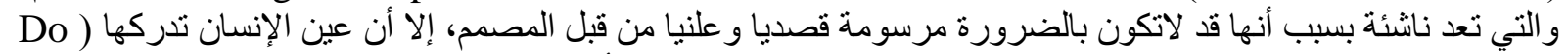

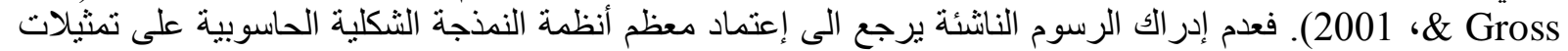

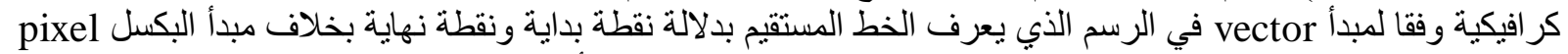

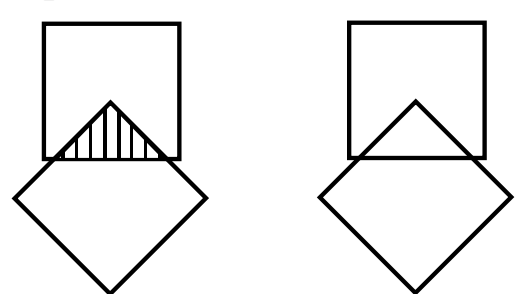

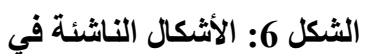
الرسوم (المصدر: الباحث)

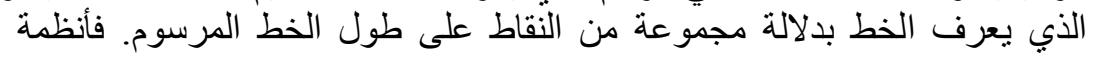

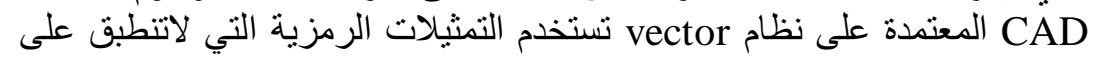

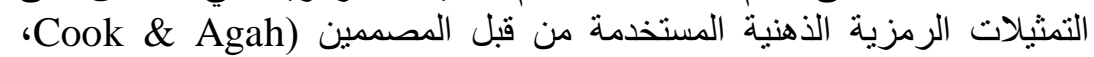

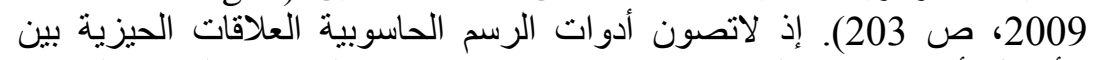

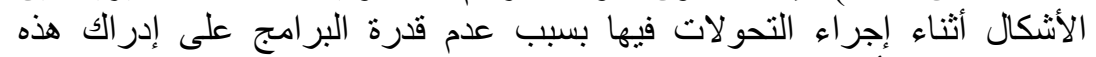

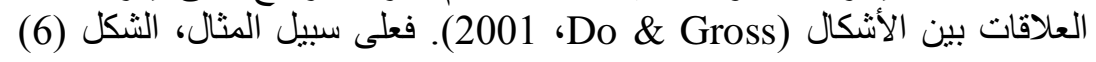

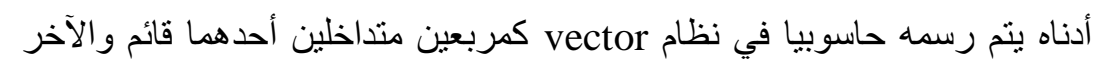

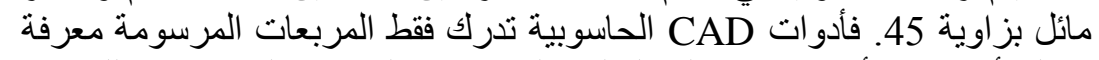

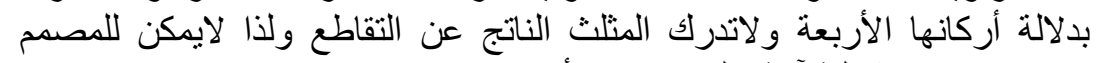
إجر اء تحو لات شكلية آنية عليه كإز احته أو تدويره.

ومن ناحية أخرى تثيد الأدبيات بإمكانيات أدوات الرسم الحاسوبية في تحوير وتطوير التصاميم الأولية بإستخدام أدوات

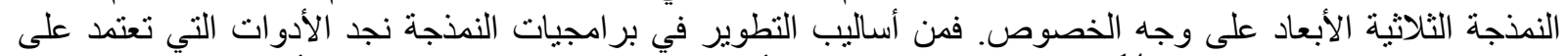

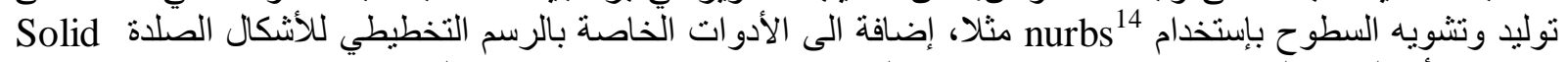

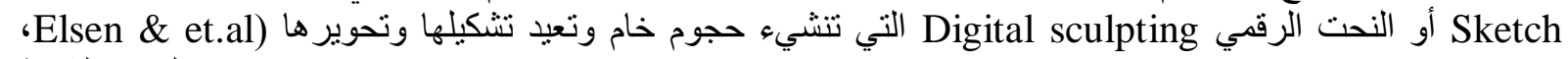

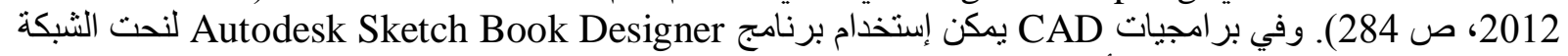

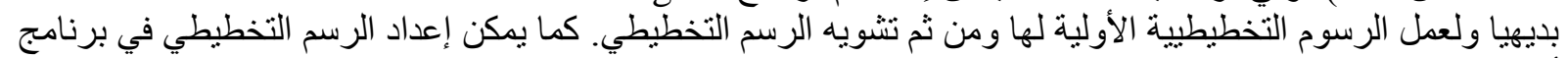

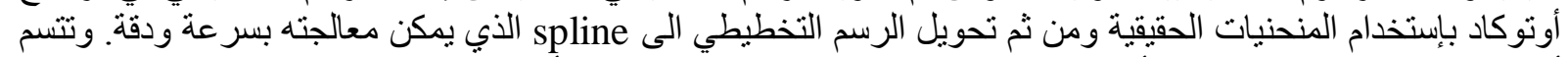

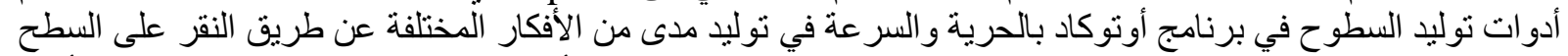

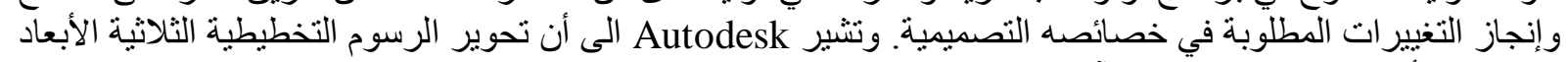

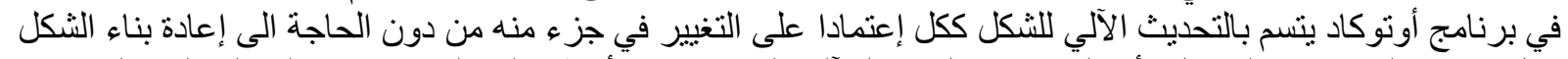

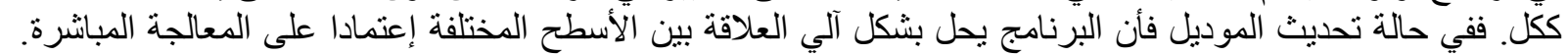

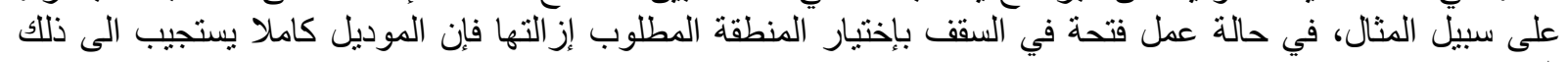

التغيير. (Autodesk) في فيل (2012)

ويشير Olsen et al. لبر امجيات النمذجة بإستخدام الرسم التخطيطي (SBIM) Sketch-based interface modelling

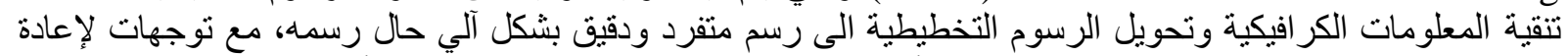

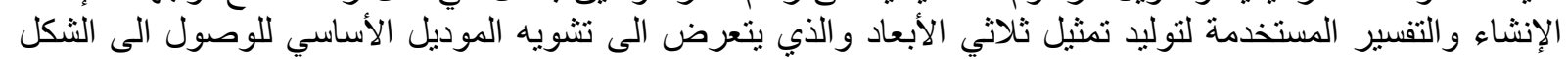

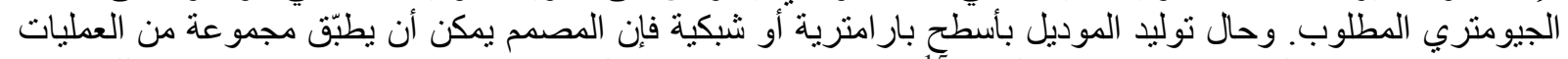

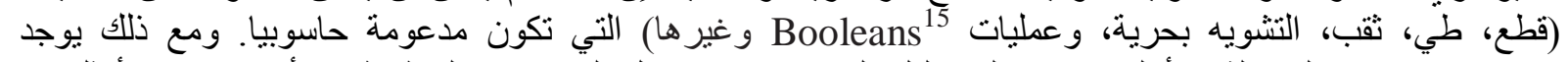

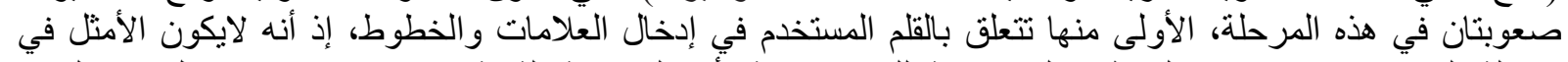

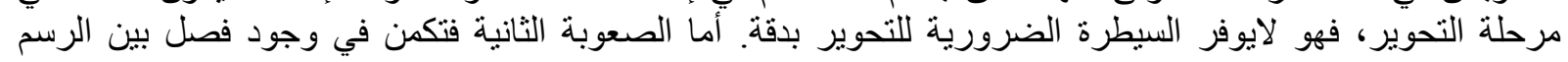

14 يمثل nurbs مختصر ا لعبارة Non-uniform rational B spline. وهو نظام لرسم السطوح المنحنية كثبكات. 15 المقصود بمصطلح Boolean operations في بر امجيات الرسم بإستخدام الحاسوب CAD هي عمليات الطرح و والتقاطع و الإتحاد. (المصدر: ( http://en.wikipedia.org/wiki/Boolean_operations_in_computer-aided_design 
التخطيطي المفاهيمي و النموذج الثناثي الأبعاد القابل للتحوير، فالتحوير ات المفروضة على النموذج لا يتم نقلها الى الرسم

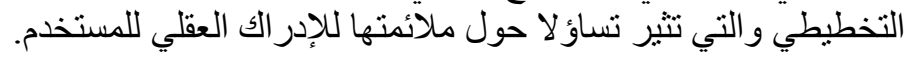

كما وتكون الأدوات الحاسوبية ذات قيمة عالية لقدر اتهم على الوصول السريع الى التصوير المرائي الثلاثي الأبعاد وتحويره

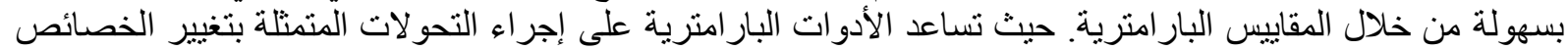

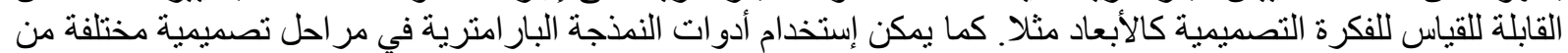

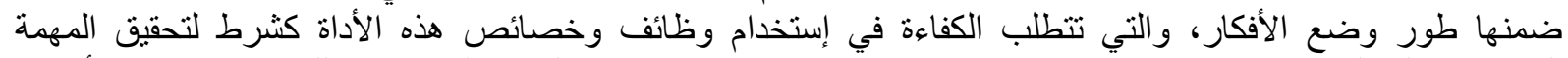

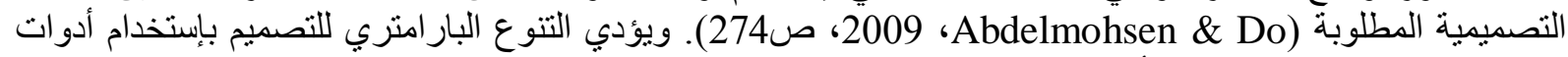

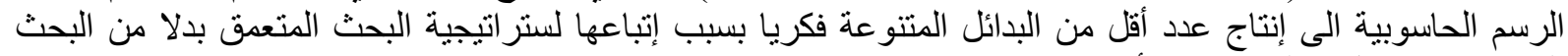

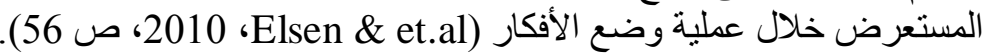

كما أن معظم واجهات المستخدم للرسوم التخطيطية تمنلك سياقا محددا مخصصا للتطييق، إذ تكون معتمدة على السياق context-dependent

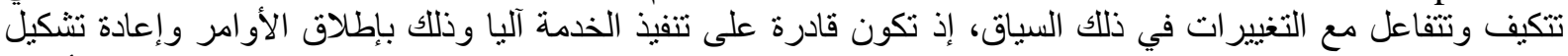

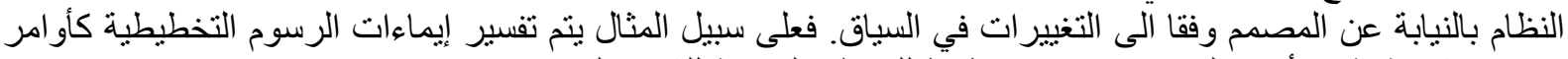

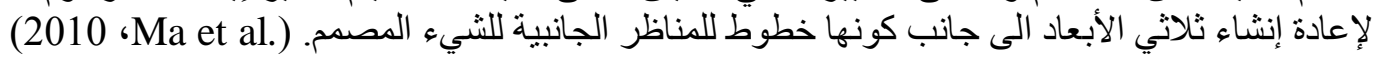

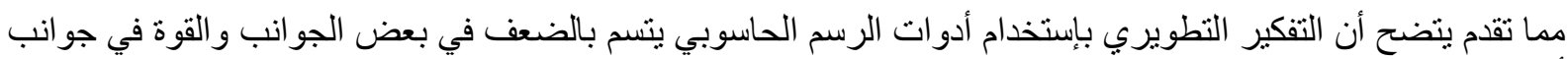

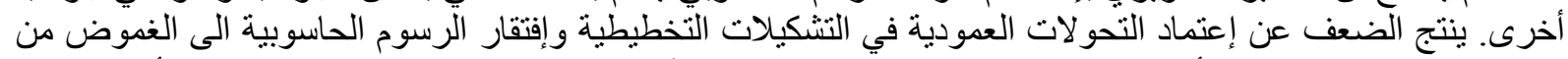

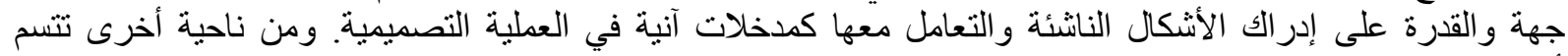

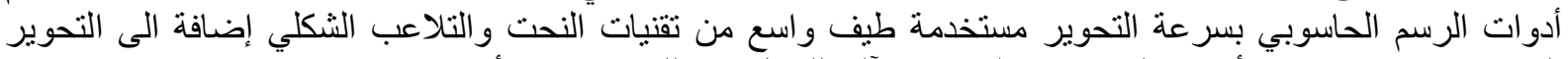

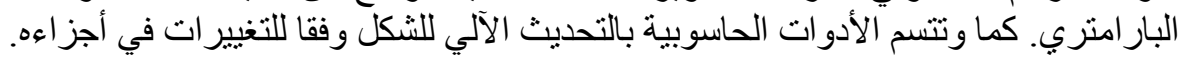

\section{2 .6 دور الرسوم الحاسوبية كأدوات للتواصل عن طريق نقل الأفكار التصميمية}

تتسم الحواسيب بشكل عام بتوفير آليات وتقنيات تواصل متقدمة بين الفريق التصميمي أو بين المصدم والعامة (Lawson،

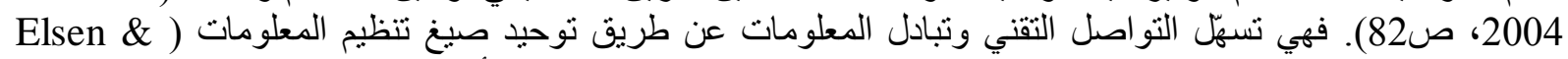
2et.al

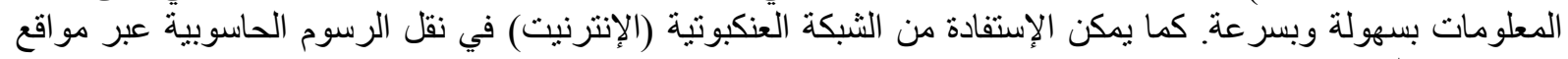

جغر افية مختلفة.

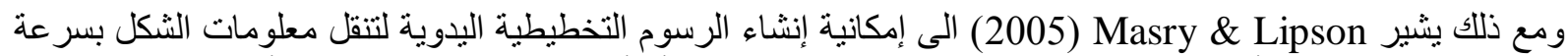

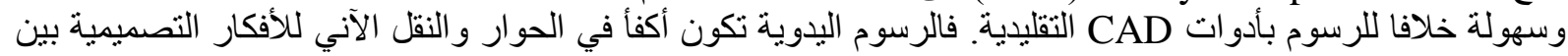

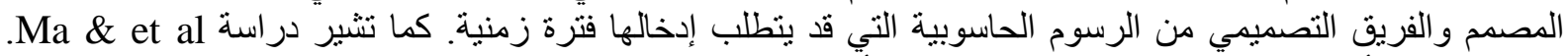

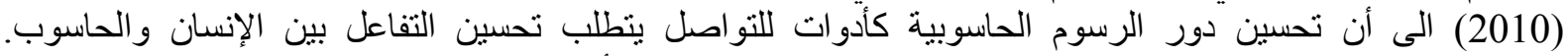

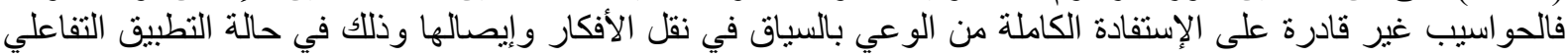

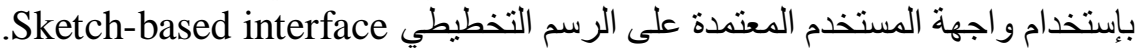

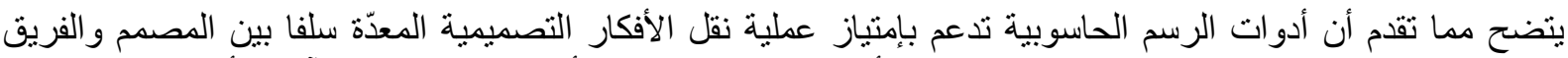
التصميمي وكذا المصمم والعامة. وبخلاف ذللك تكون أدوات التئة الرسم الحاسوبي أقل كفاءة في النقل الآني للأفكار التصميمية.

\section{2 .6 دور الرسوم الحاسوبية كأدوات للتواصل عن طريق تفسير الأفكار التصميمية}

ضمن الدور التفسيري للرسوم اليدوية، تطرح الأدبيات دورا إضافيا لادوات الرسم الحاسوبي تستلزم فيه قدرة البرنامج

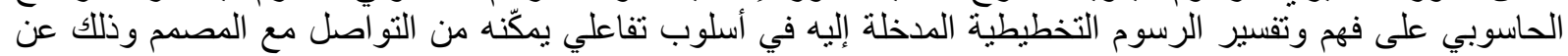

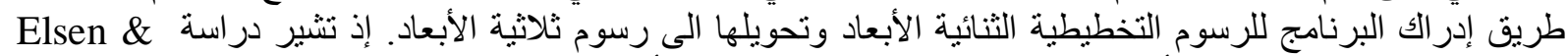
et.al

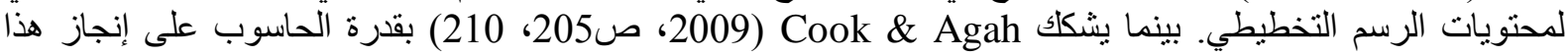

context-sensitive ${ }^{16}$ 


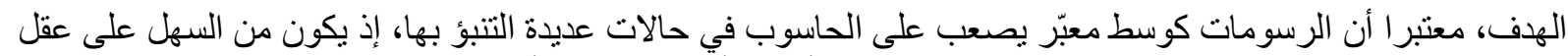

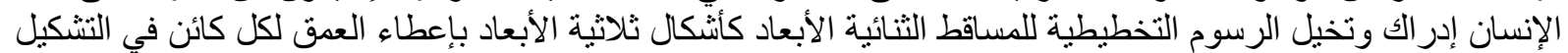

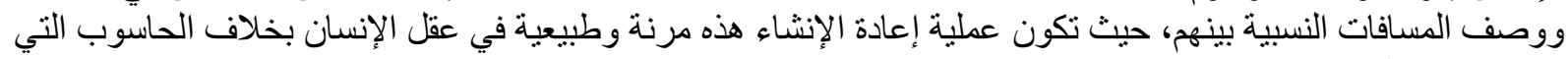
تكون صعبة التطبيق فيه.

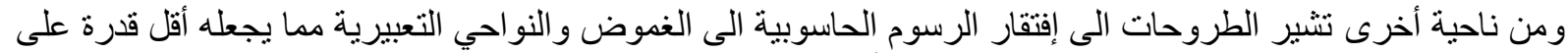

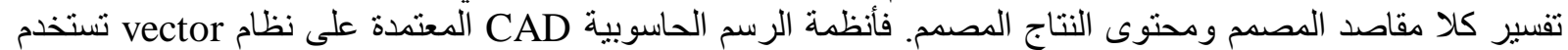

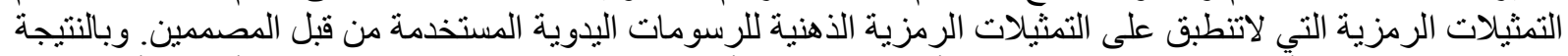

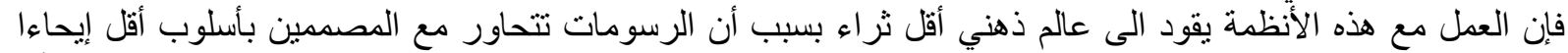

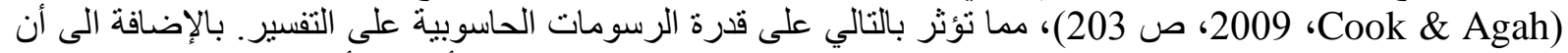

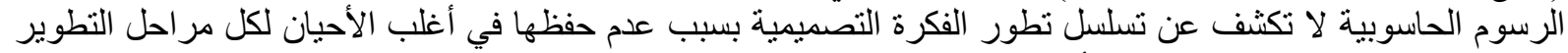
و التحوير المنجز على رسوم الفكرة الأولية.

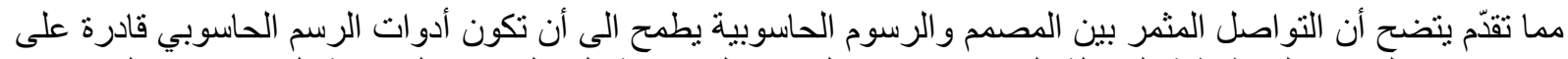

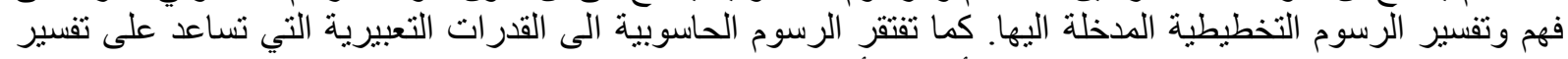

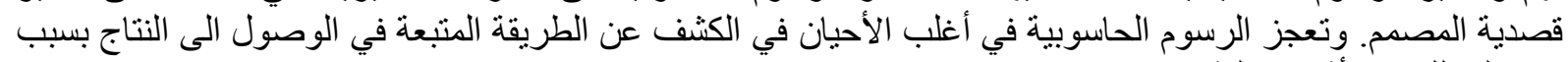
إستبدالها للرسوم أثناء عملية تنقيحها.

\subsection{6 دور الرسوم الحاسوبية كأدوات لتوثيق الأفكار التصميمية}

تتسم أنظمة الرسم الحاسوبية بقدرة خزن فائقة للمعلومات التصميمية. إذ يؤكد التوسية Yu \& Zhang (2007) أنّ الرسوم

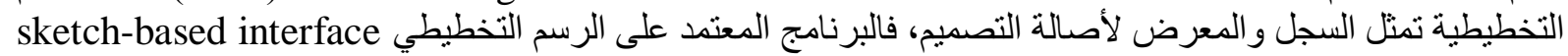

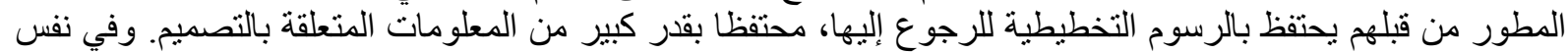

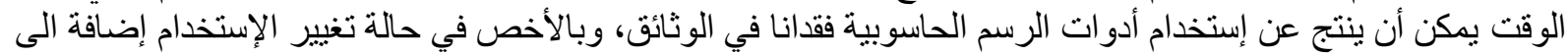

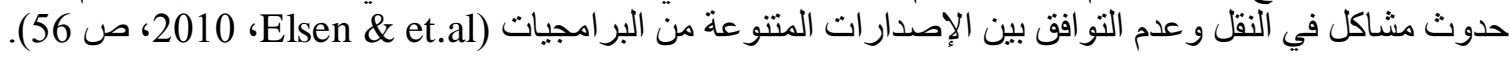
ومن ناحية أخرى، فإن أسلوب التنقيح للرسوم الحاسوبية يؤدي الى فقدان وثائق تصميمية مهمة بسبب إستبدال الرسم

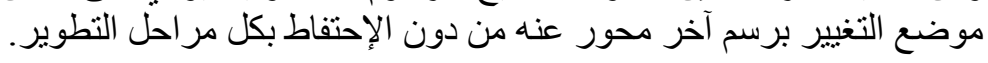

مما تقدم بتضح أن أدوات الرسم الحاسوبي توفر إمكانيات جيدة لخزن وتوثيق الأفكار التصميمية النهائية للرجوع إليها لاحقا من قبل المصدم، إلا أنها تفتقر الى توثيق مر احل التطور التفيلية.

\section{6 دور تقنيات الرسم الحاسوبية في الممارسات المهنية}

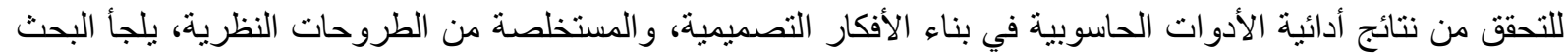

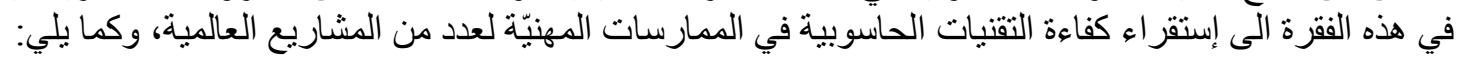

1.3.6 مشروع New Elephant House ، المصمم من قبل Foster \& Parteners، إكتمل إنشاؤه في عام 2008

في مدينة كوبنهاكن، الدانمارك.

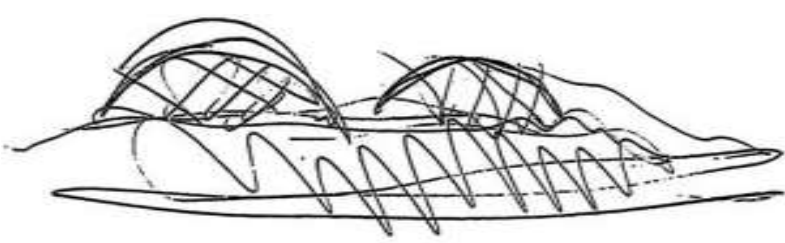

Foster الشكل 7: رسم تخطيطي يدوي للمشروع للمعماري

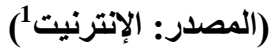

في عملية تصميم المشروع، إقترح فوستر في الرسم التخطيطي البدوي الموضح في الشكل (7) هيكلين لقبتين إحداهما أكبر من الأخرى ناشئتين من الفضاءعات الخئ الخارجية

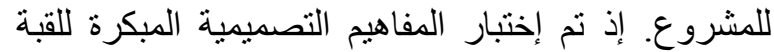

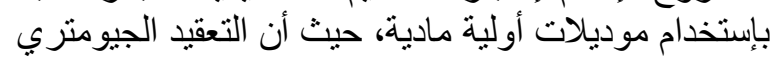

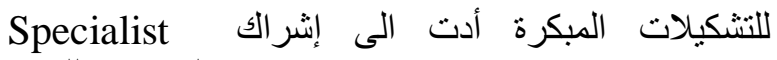
Modelling Group (SMG) التخطيطي الرقمي الثناثي الأبعاد لموديلات CAD. 


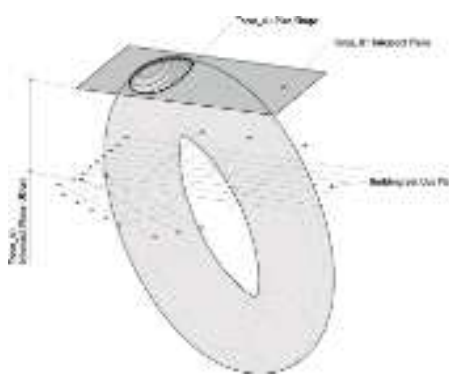

الثكل 8: الثم بار امتري للقبة

(المصدر: الإنترنيت

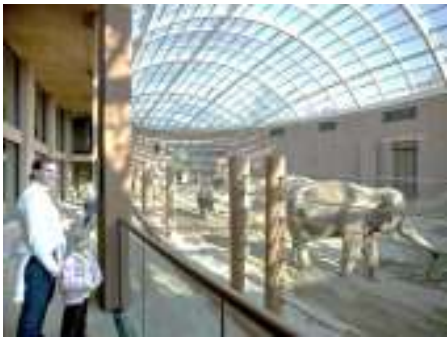

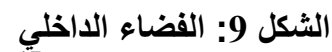

للقبة (المصدر: الإنترنيث الفضيثاء)
(2008، (Peters)

إذ تم تطوير نظام بار امنري كأداة تصميمية من قبل الفريق التصميمي لإستكثاف

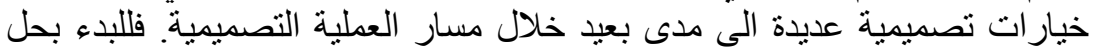
التصميم بلغة الخصائص البعدية للفضاءات مدات والهياكل، تم إنتاج موديلات تخطيطية بإستخدام CAD لإستكشاف الشكل الجيومثري من خلال رسوم لنماذج ثلاثية الأبعاد

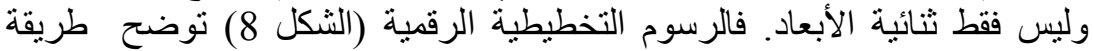
إشتقاق القبة من الشكل الجيومتري لإطار العجلة torus الذي تم إنئة إنشاؤه بواسطة

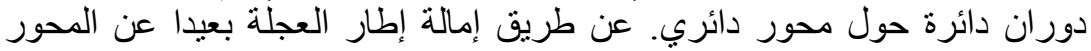

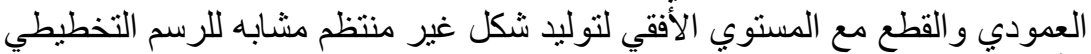

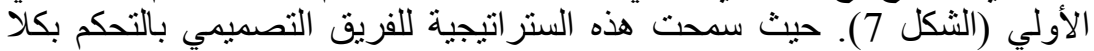

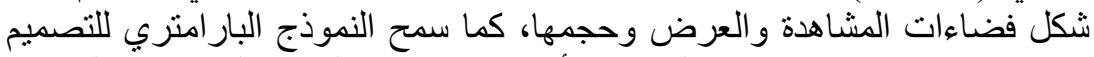

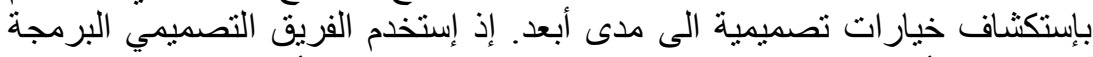

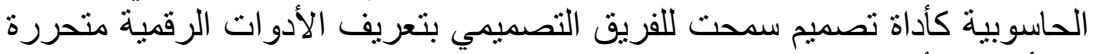

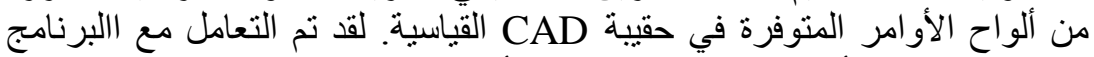

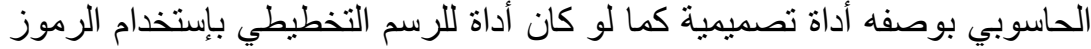

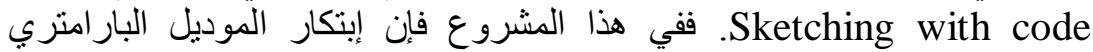
وإستخدام البرمجة الحاسوبية لتوليد بنية السقيفة والتزجيج لم يكن طريقة فيقة لتوليد أساليب جديدة و غير مسبوقة للتعبير فحسب، بل أتنج تنوعات عديدية أمكن توليدها و إختبار ها. فإستخدام الحاسوب في العملية التصميمة شوهية هد كأسلوب لتوليد بلئ بنية السقيفة وزجاجها بكفاءة أكثر من الطرائق التقليدية. (Peters، 2008)

بناءا عليه يتضح أن توظيف الأدوات الحاسوبية في التصميم الأولي ومشروع New Elephant House قد عزز من مهام التفكير التجريبي بأنو اعه التحليلي و الإستكثافي والمقارن والتئي التيمي إضافة الى التفكير التحولي.

2.3.6 مشروع ناطحة سحاب Swiss Re Tower، المصمم من قبل Foster \& Parteners، إكتمل إنشاؤه في عام

إستخدم الفريق التصميمي برمجية تصميم من شركة Bentley Systems في صنع الثكل المفاهيمي. إذ أستخدمت عملية

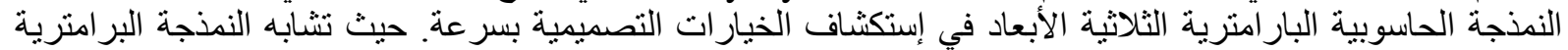

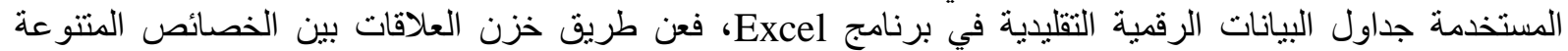

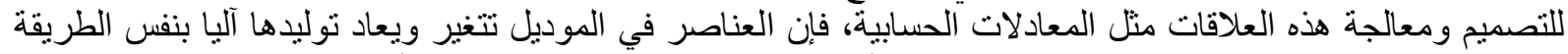

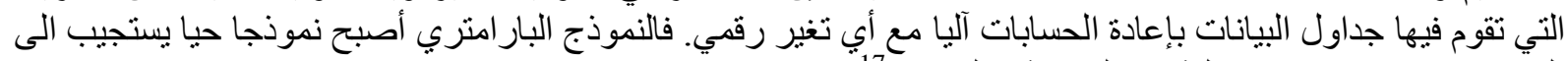

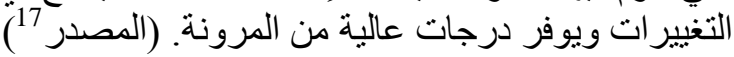
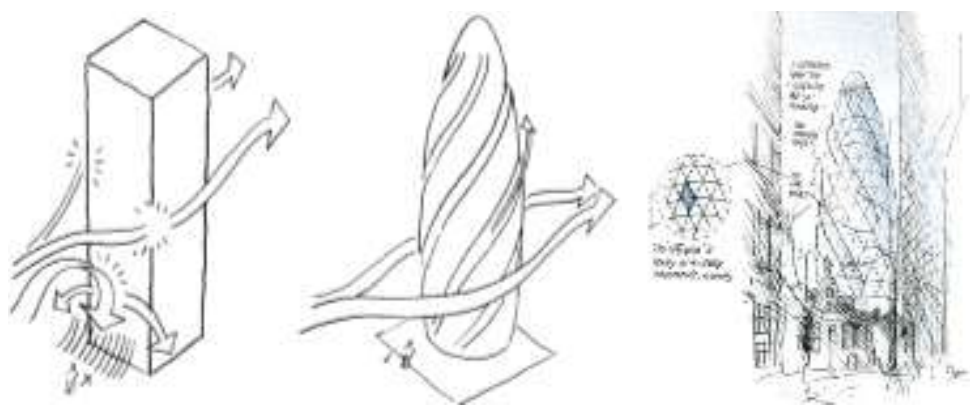

الشكل 10: رسوم تخطيطية يدوية للتفكير التحليلي في مشروع ناطحة السحاب Swiss Re (المصدر: الإنترنيت 18) 

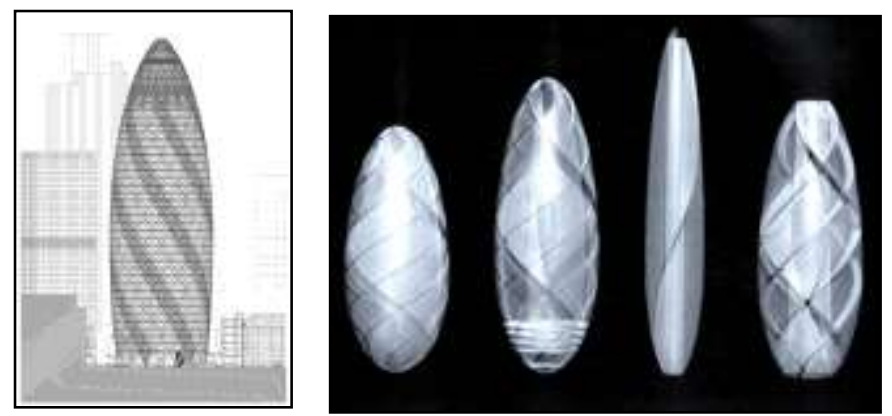

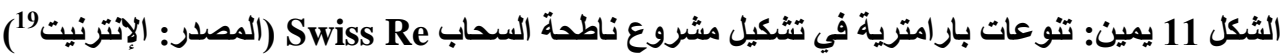

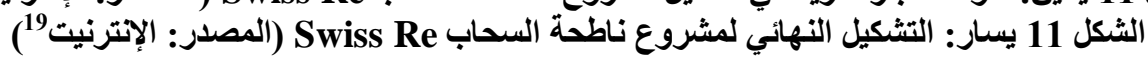

مما تقدم يتضح أن توظيف الأدوات الحاسوبية في التصميم الأولي لمشروع برج Swiss Re يدعم مهارات التفكير التجريبي بأنو اعه: التحليلي و الإستكثافي والمقارن التيف والتقييمي إضافة التى التفكير التحولي.

3.3.6 مشروع مسابقة دولية لتصميم Fast Train Station, Florence، للمعمارية زهاء حديد، عام 2002

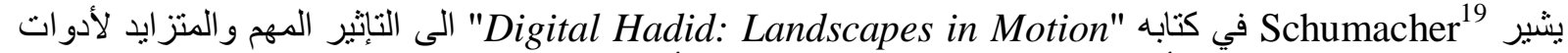

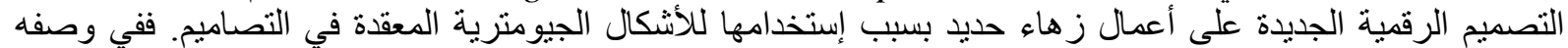
لمشروع تصميم محطة القطار في Schumacher يشير الى إختلاف هذا المشروع عن بقية مشاريع زهاء

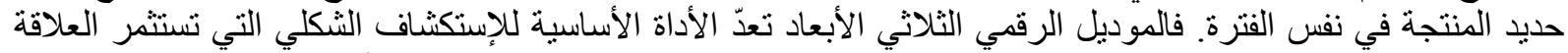

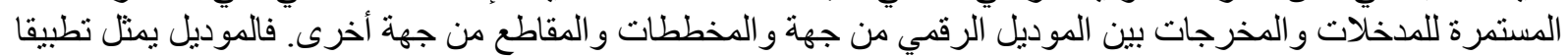

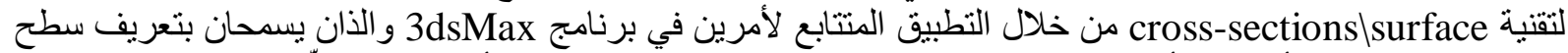

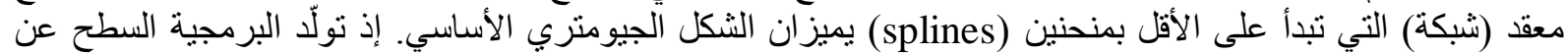

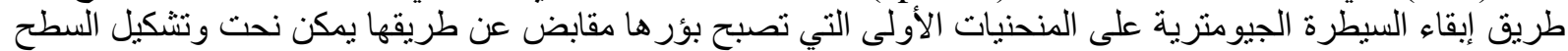

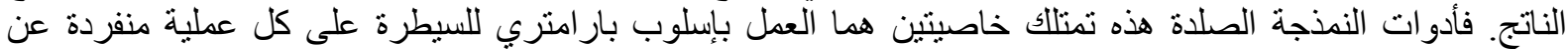

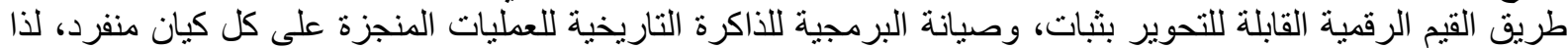

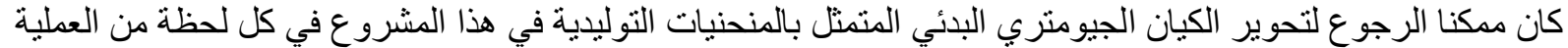

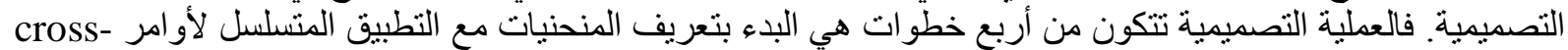

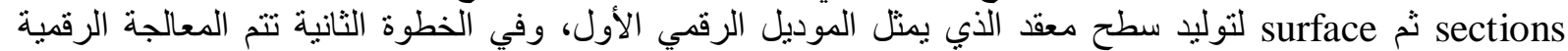

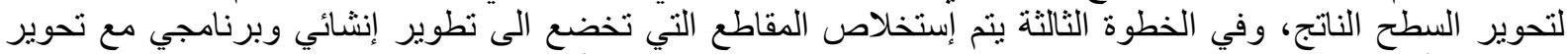

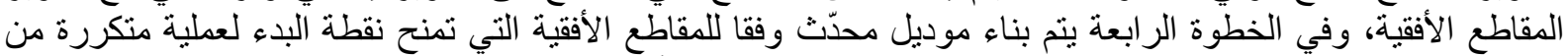

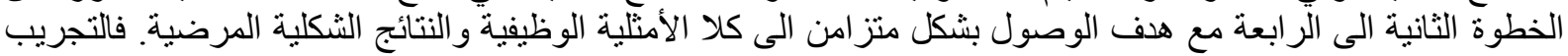
على الموديلات الرقمية في عملية تصميم المشروع بتسم بالأهمية العظمى. (Schumacher، 2004)

مما تقدّم يمكن القول أن نوظيف الأدوات الحاسوبية في التصميم الأولي لمشروع محطة القطار في Florence بداعم

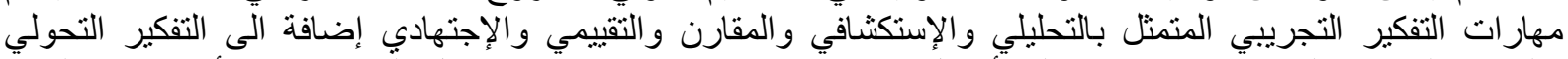

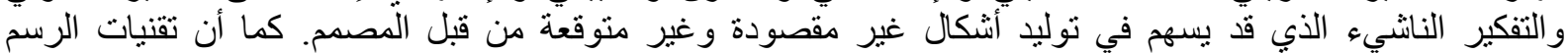

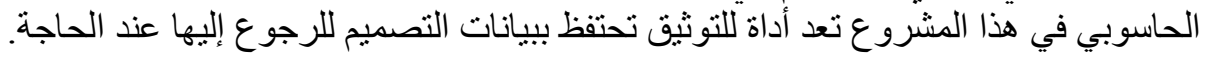

4.3.6 مشروع Setun Hills Business Park، المصمم من قبل BRT Architekten، في مدينة موسكو، إبتدأ

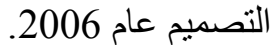

إستخدم الفريق التصديمي برمجيات MicroStation V8 مع المنتجة من قبل شركة Bentley Systems الأولية. فبرمجية MicroStation V8 ساعدت المصممين في الدراسة و الفهم الصائب للعلاقات المعقدة بين الأبنية والبيئة 


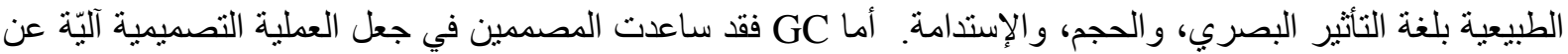

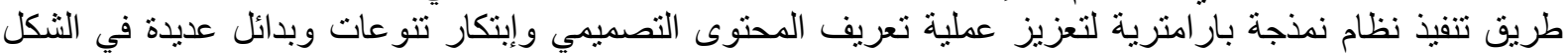

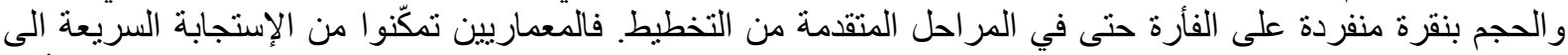

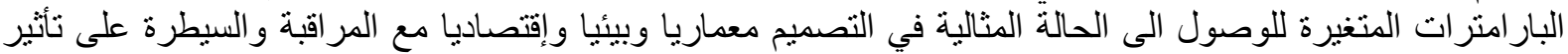

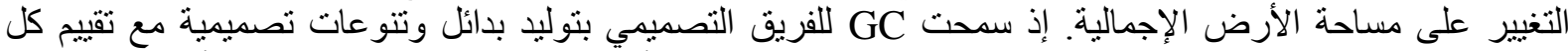

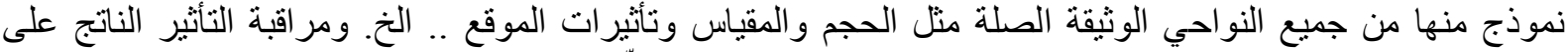
المساحة الإجمالية مع كل بديل تصميمي. فالبر امجيات المستخدمة هنا مكّنت المصممين من تقييم التصميم خلال المر احل

الأولية (20).

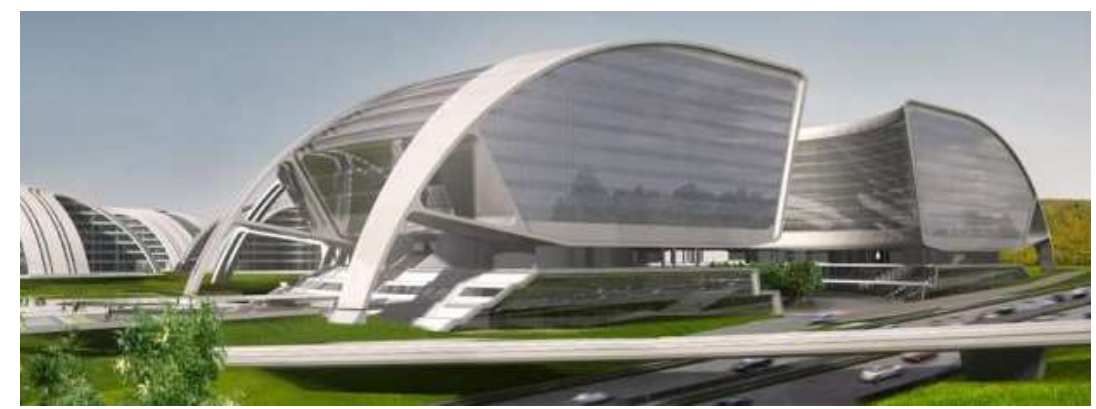

الثكل 12: موديل حاسوبي لمشروع Setun Hills Business Park (المصدر: الإنترنيت 21)

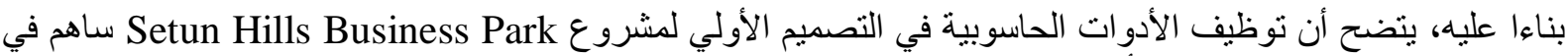

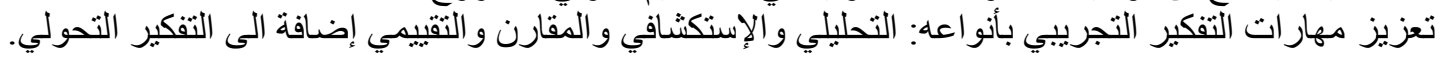

5.3.6 مشروع Aviva Stadium، المصدم من قبل Populous ، في مدينة دبلن، إكتمل إنشاؤه في عام 2010

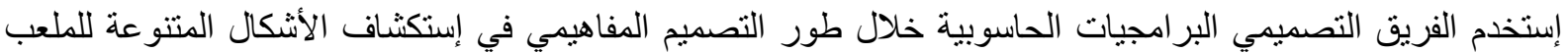

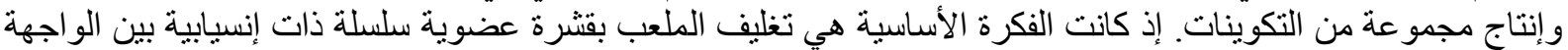

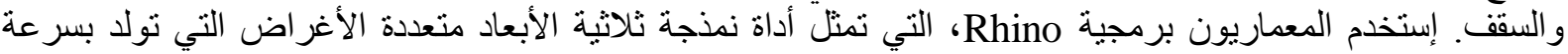

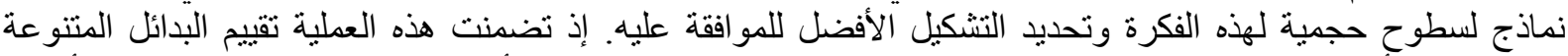

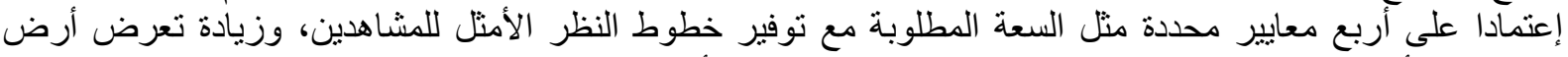

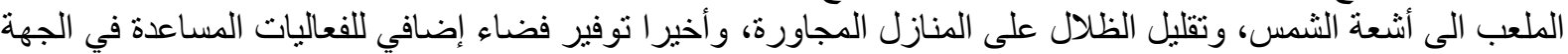
الثرقية. حيث قامت الجهة المستفيدة بتفص البدائل المنتجة حاسوبيا وإختيار أحدها. (Eastman et al.

صن399، 400)

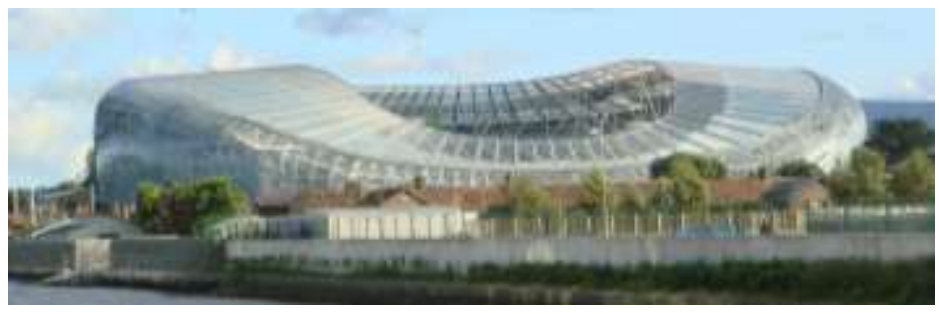

الثكل 13: صورة جوية لمشروع ملعب Aviva (المصدر: الإتترنيت22)

مما تقدم يتضح أن توظيف الأدوات الحاسوبية في التصميم الأولي لمشروع Aviva Stadium يدعم مهارات التفكير

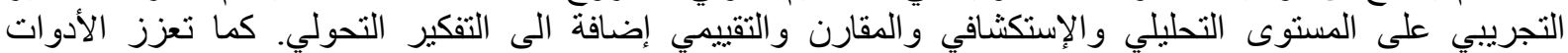

CAD User AEC Magazine, Vol 21, No 01 - January/February مقالة في Moscow's going Green! 20 http://caduser.com/reviews/reviews.asp?a id=409 http://www.betonlana-report.com/wp-content/uploads/2012/03/setunhillsbusinnespark_12.jpg ${ }^{21}$ http://commons.wikimedia.org/wiki/File:Aviva_Stadium\%28Dublin_Arena\%29.JPG ${ }^{22}$ 
الحاسوبية في هذا المشروع من عملية التواصل عن طريق تبادل المعلومات بين أفراد الفريق التصميمي بالإضافة الى الفريق التصميميي و الجهة المستقيدة.

6.3.6 مشروع Sutter Medical Center، المصدم من فبل Devenney Group، في Castro Valley ، في كاليفورنيا، إكتمل إنشاؤه في عام 2012.

إتفق الفريق التصميمي على إستخدام التكنلوجيا الثثلاثية الأبعاد لتسهيل تبادل المعلومات رقميا بإستخدام نفس معلومات

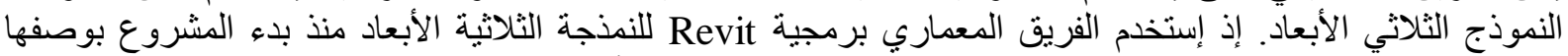

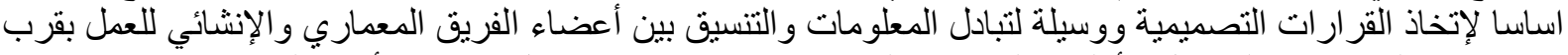

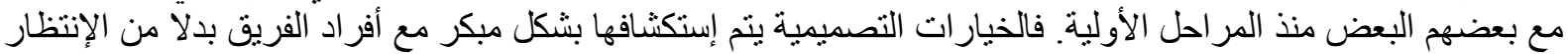

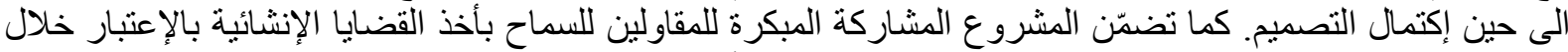

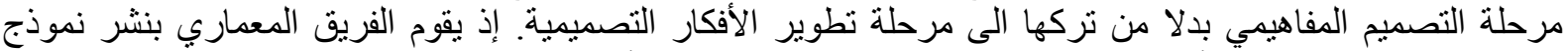

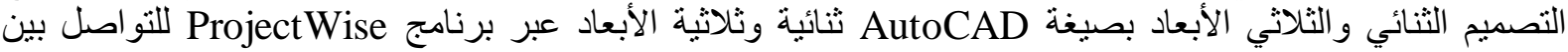

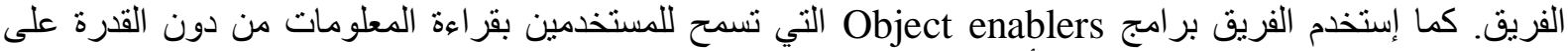

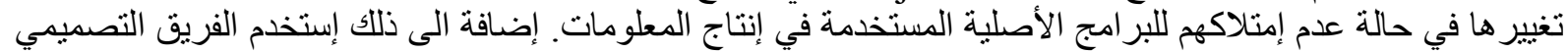

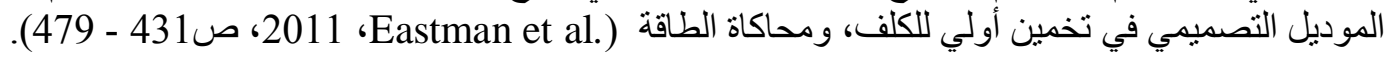

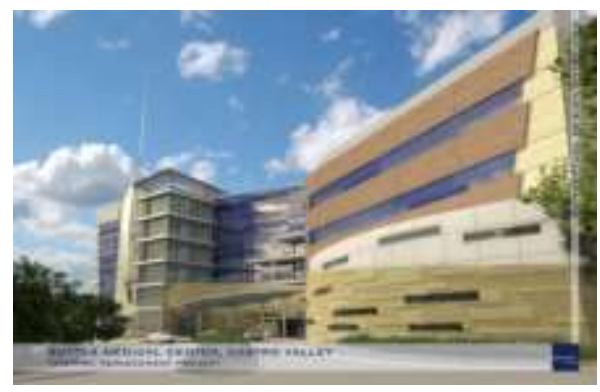

الثكل 14: صورة لمشروع Sutter Medical Center (المصدر: الإنترنيت

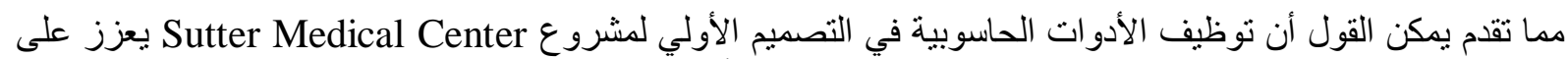

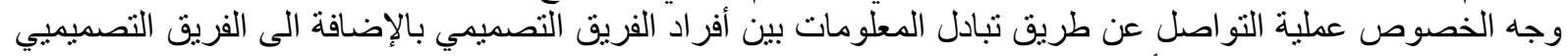

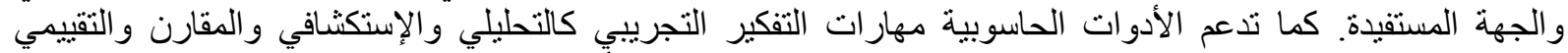
إضافة الى التفكير التحولي. إضافة الى إستخدامها لتقنيات تسهم في توثيق الأفكار التصميمية.

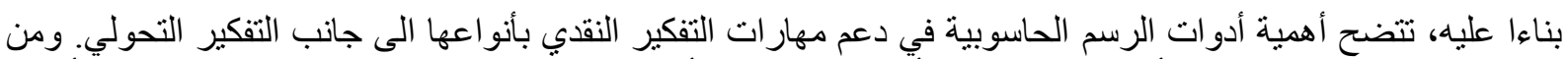

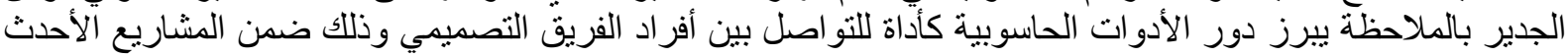
في عينة الدراسة. 
جدول 2: دور تقتيات الرسم الحاسوبية في مرحلة وضع الأفكار التصميمية (المصدر: الباحث)

\begin{tabular}{|c|c|c|c|c|c|c|}
\hline 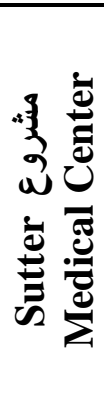 & 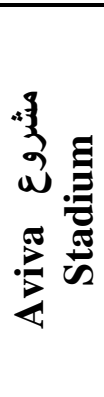 & 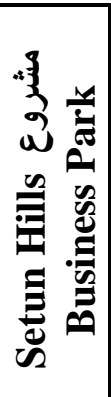 & 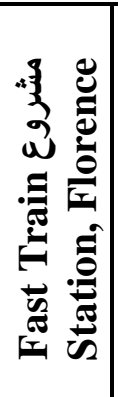 & 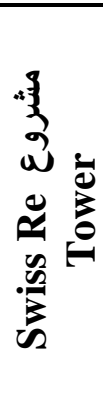 & 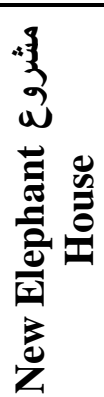 & دور تقتيات الرسم \\
\hline & & & & & & أداة للتفكير التخيلي \\
\hline & & & & & & أداة للتفكير التأملي \\
\hline & & & & & & أداة للتفكير الإسترجاعي \\
\hline$\bullet$ & $\bullet$ & $\bullet$ & $\bullet$ & $\bullet$ & $\bullet$ & أداة للتفكير التحليلي \\
\hline$\bullet$ & $\bullet$ & $\bullet$ & $\bullet$ & $\bullet$ & $\bullet$ & أداة للتفكير الإستكشافي \\
\hline - & $\bullet$ & $\bullet$ & $\bullet$ & $\bullet$ & $\bullet$ & أداة للتفكير المقارن \\
\hline$\bullet$ & $\bullet$ & $\bullet$ & $\bullet$ & $\bullet$ & $\bullet$ & أداة للتفكير التقييمي \\
\hline & & & & & & أداة للتفكير الإجتهادي \\
\hline$\bullet$ & $\bullet$ & $\bullet$ & $\bullet$ & $\bullet$ & $\bullet$ & أداة للتفكير التحولي \\
\hline & & & $\bullet$ & & & أداة للتفكير الناشىع \\
\hline$\bullet$ & • & & & & & ألفريق لنقل الأفكار من المصمم الى \\
\hline & & & & & & العامة لنقل الأفكار من المصمم الى \\
\hline & & & & & & أداة لتفسير مقاصد المصمم \\
\hline & & & & & & أداة لتفسير محتوى التصميم \\
\hline & & & & & & أداة لتفسير طريقة التصميم \\
\hline$\bullet$ & & & $\bullet$ & & & أداة للتوثيق الأفكار التصميمية \\
\hline
\end{tabular}

7. الإستتتاجات: التحليل المقارن بين تقتيات الرسم اليلوي وتقتيات الرسم الحاسوبي

يمكن للبحث أن يلخص الجوانب الإيجابية و السلبية في تقنيات الرسم الحاسوبية مقارنة بالمهام التي تتجز ها الرسوم اليدوية في مرحلة وضع الأفكار التصميمية، وكما يلي:

1.7 الرسوم الحاسوبية كأدوات للتفكير المبتكر

مقارنة بالرسوم اللدوية، يمكن القول أن تقنيات الرسم الحاسوبية تسهم بشكل فاعل في تفعيل اللغة الهندسية المعقدة للرسومات التي يصعب تمثيلها يدويا. ومع ذلك فهي تفتقر الى مهارات التفكير المبتكر التخيلي، والتأملي والإسترجاعي التئي

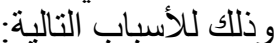
• إفتقار أدوات الرسم الحاسوبية الى التلقائية والمباثرية والمرونة في التنفيذ الآني لأفكار الدصمم مقارنة بالرسم

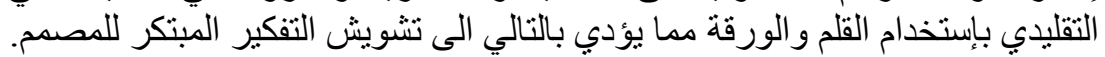




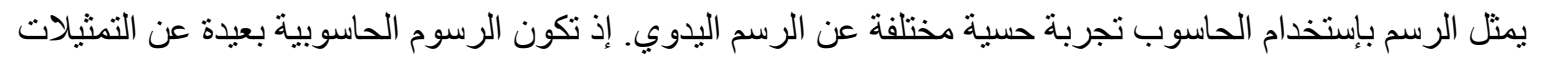

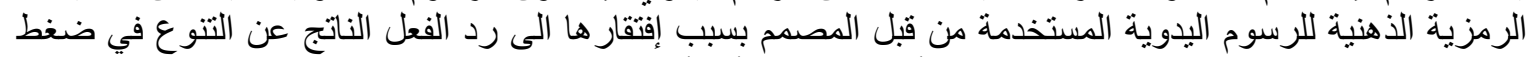

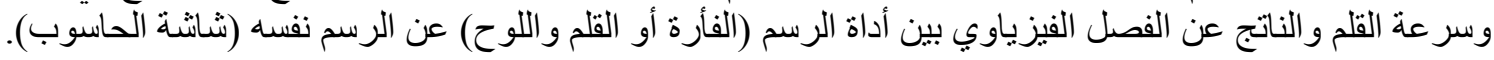

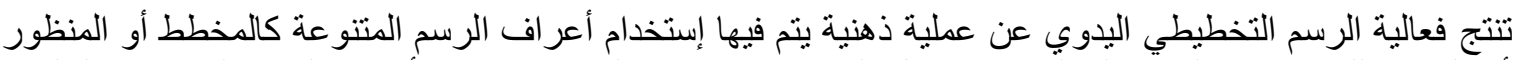

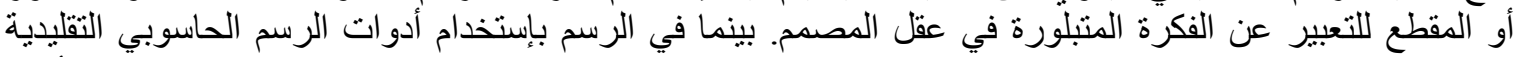

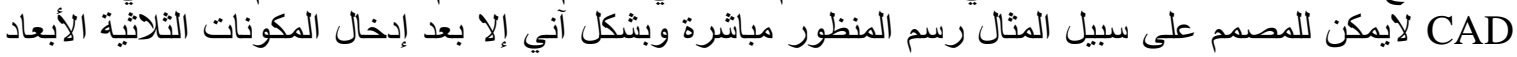

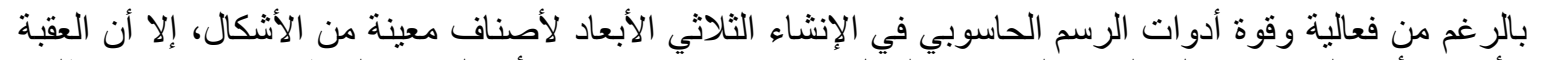

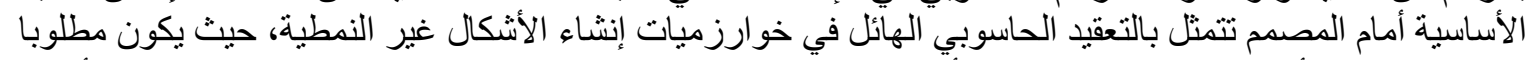

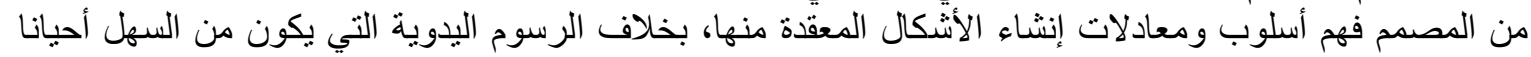

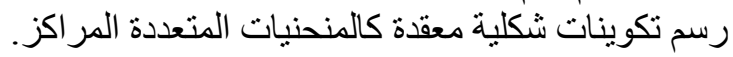

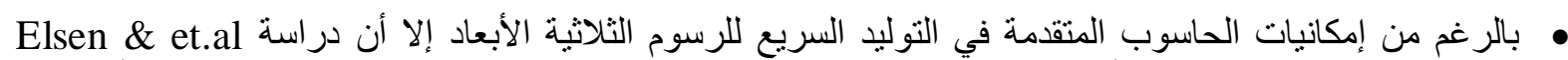

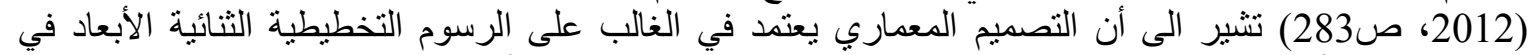

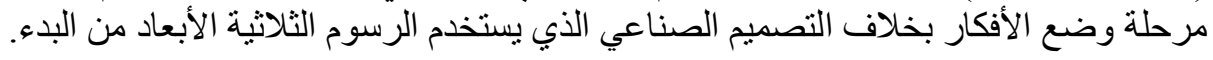

2.7 الرسوم الحاسوبية كأدوات للتفكير النقدي

تمتلك الأدو ات الحاسوبية طاقات هائلة في دعم مهارات التفكير التحليلي و الإستكثافي و المقارن والتقييمي. إذ تتسم بما يلي:

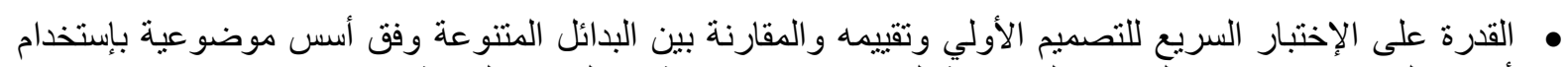

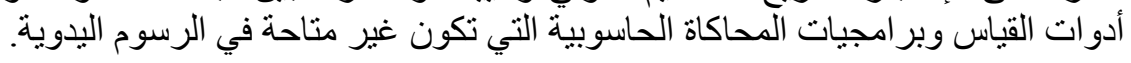

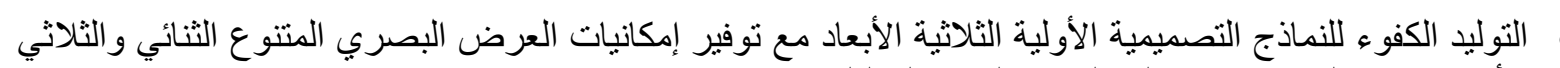

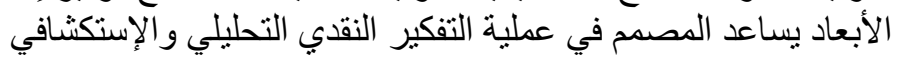
ومن ناحية أخرى تبرز بعض المعوفات للتفكير النقدي والناتجة عن: وإنثاء الرسوم بإستخدام الفأرة وبالإعتمادا على إختبار العناصر الجاهزة من القو بائم تمنع المصدم من النقد و التمعن أنثاء التفكير.

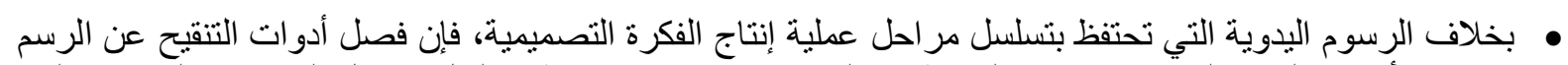

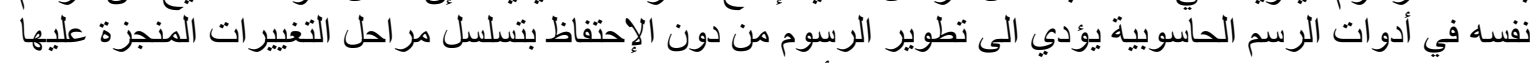

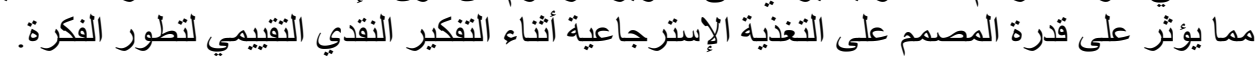

3.7 الرسوم الحاسوبية كأدوات للتفكير التطويري

تعزز الأدوات الحاسوبية من مهار ات التفكير التحولي، إذ تتسم بالنواحي الإيجابية التالية:

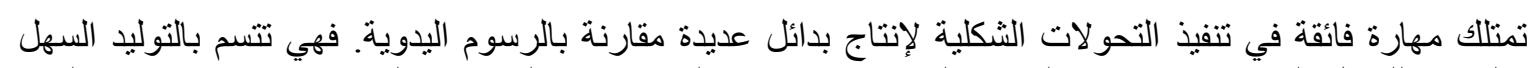

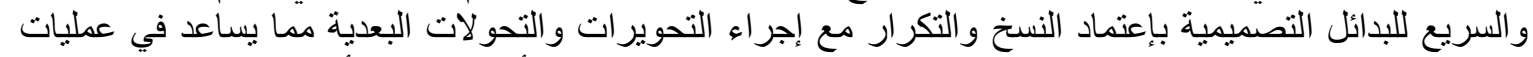
التفكير النقدي الإستكثافي و المقارن بخلاف الرسوم اليدوية التي تنطلب فترة أطول وجهدا أكبر لإعادة التهاد رسم كل بديل

من جديد.

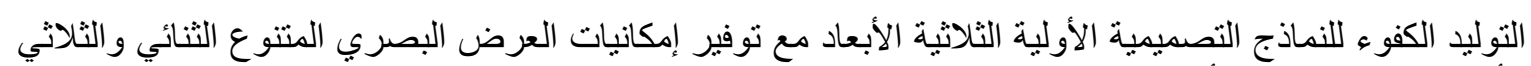

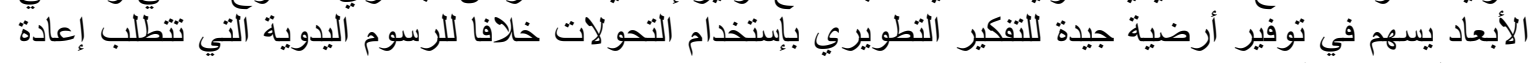
رسم كل منظر على حدة. • القدرة على التحديث الآلي للتشكيل الناتج عند إجراء التحوير في أي جزء منه بخلاف الرسوم اليدوية التي تسنتزم إعادة الرسم. من ناحية أخرى، يمكن تشخيص الجو انب السلبية التالية المؤثرة على مهار ات التفكير التطويري للتصميم وهي: 
• يكون نهج التحو لات في الرسوم الحاسوبية متعقا بحيث ينتج بدائل أقل تنوعا، بخلاف الرسوم اليدوية التي يكون

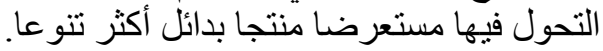

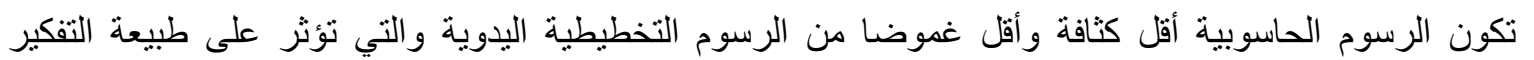

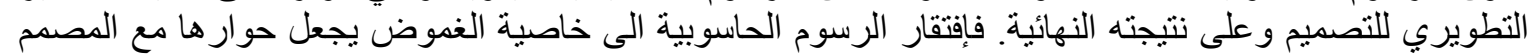

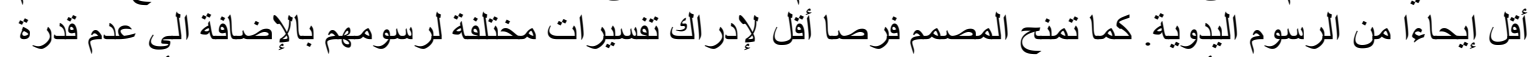

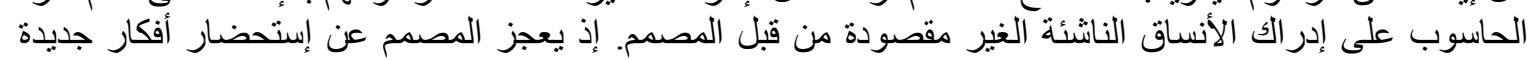

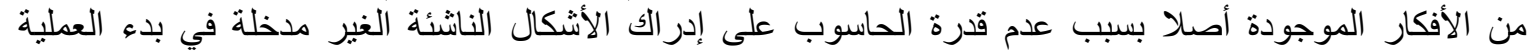

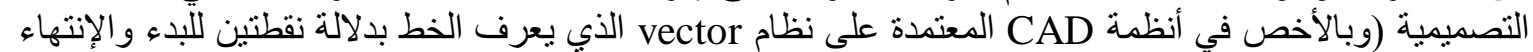

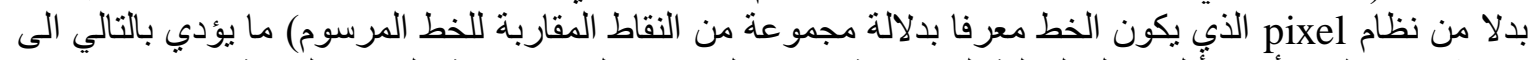
إستكثاف وتطوير أفكار أقَّل خلال العملية التصميمية وبنفس الفترة من الزمن مقاط مقارنة بالرسوم اليدوية.

4.7 الرسوم الحاسوبية كأدوات لنقل الأفكار

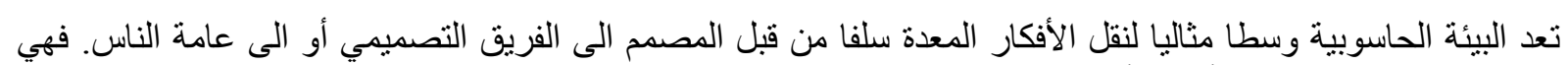

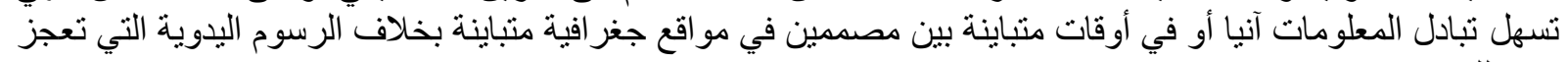
عن ذلك. من جهة أخرى، تتسم الرسوم الحاسوبية بالعجز عن النقل الآني للأفكار التصميمية المتبلورة حاليا في ذهن المصمم الى الى

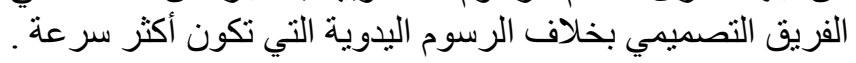

5.7 الرسوم الحاسوبية كأدوات لتفسير الأفكار

لاتعد الرسوم اليدوية وسطا ملائما لتفسير الأفكار التصميمية وذلك للأسباب التالية

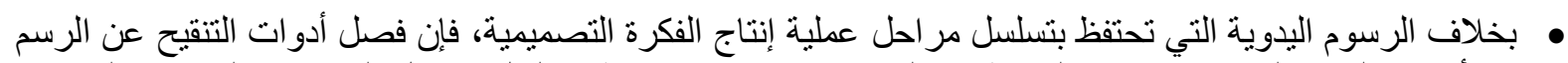

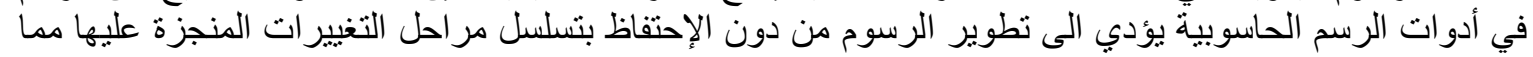

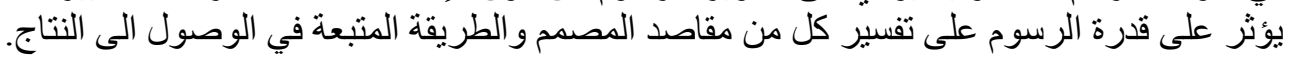

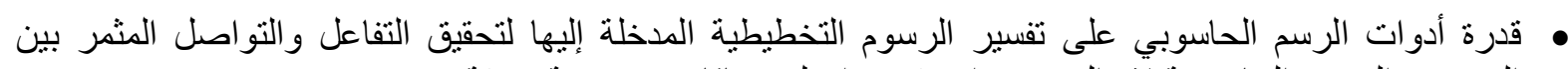

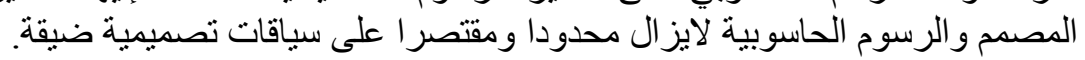

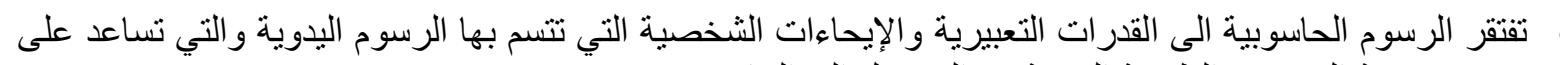

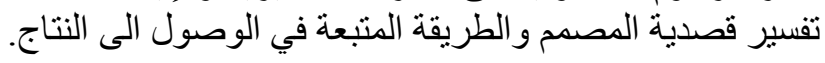

\section{7 الرسوم الحاسوبية كأدوات لتوثيق الأفكار}

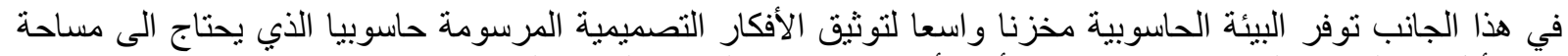

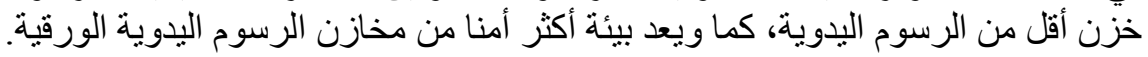

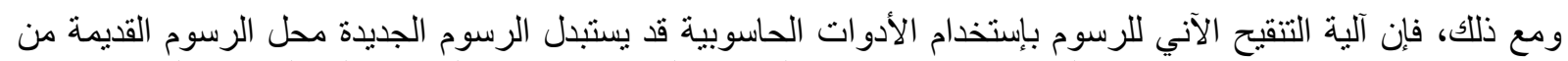

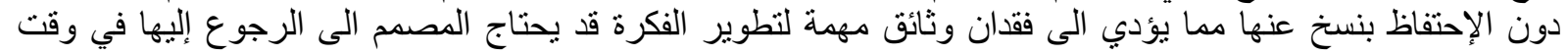

\section{8. الإستتتاجات: دور تقتيات الرسم الحاسوبية في الممارسة المهنية}

أظهرت المشاريع المصممة من فبل المعماري Norman Foster حضورا بارزا للرسوم التخطيطية اليدوية في بلورة

الفكرة التصميمية بوصفها أداة للتفكير المبتكر التخيلي في كلا مشروعي Swiss Re و New Elephant House Tower 
كما أفرزت نتائج الدراسة العملية نوجها واضحا في نوظيف أدوات الرسم الحاسوبية خلال طور التصميم الدفاهيمي

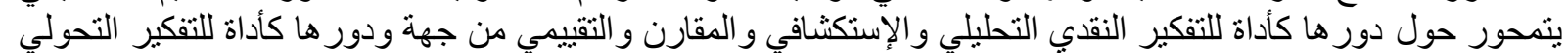
من جهة أخرى.

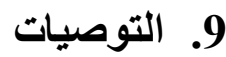

• لحد الآن لم يقدم مطوري الأنظمة الحاسوبية بر امجيات رسم تخطيطي sketch-based interface systems بنفس التس كفاءة التفكير المبتكر الذي تتسم به تقنية الرسوم التخطيطية اليدوية. و وعليه يوصي البحث بضئ بضرورة عدم التخلي عن تقنيات الرسم اليدوية في التعليم و الممارسة المعمارية الرسية.

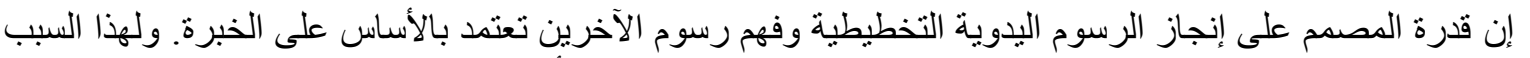
يجب تطوير مهارة الطلبة على الرسم اليدوي التخطيطي ضمن المر احل الأولية لتعليم التصميم المعماري.

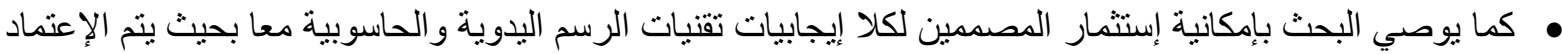
على الرسوم اليدوية في طور التفكير المبتكر والرسوم الحاسوبية في طوري التفكير التجريبي النقدي والتطويري.

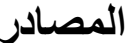

1. القزاز، ضحى عبد الغني، تقنيات الرسوم اليدوية ـ دورها في التصميم المعماري، مجلة هندسة الر افدين، مجلد 16، العدد 3،

2. Autodesk, Conceptual Design Made Easy with AutoCAD, White paper, 2012.

3. Cook, M. T., Agah, A., "A survey of sketch-based 3-D modeling techniques", Interacting with Computers, 21, 2009, 201-211.

4. Do, E. Y. \& Gross M. D., Thinking With Diagrams in Architectural Design, Artificial Intelligence Review, 15: 135-149. Kluwer Academic Publishers, the Netherlands, 2001.

5. Eastman, C., Teicholz, P., Sacks, R., and Liston, K. BIM Handbook: A Guide to Building Information Modeling for Owners, Managers, Designers, Engineers and Contractors. Wiley. Hoboken N.J , 2011.

6. Elsen, C., Demaret, J.-N., Yang, M. C. \& Leclercq, P., Sketch-based interfaces for modeling and users'needs: Redefining connections. Artificial Intelligence for Engineering Design, Analysis and Manufacturing / Volume 26 / Special Issue 03 / August 2012, pp 281-301.

7. Elsen, C., Darses, F.,\& Leclercq, P. , An anthropo-based standpoint on mediating objects: evolution and extension on industrial design practices, Design Computing and Cognition (Ed.) Gero, J., Stuttgart: Springer, 2010, pp 55-74.

8. Holzner, S., Sams Teach Yourself Google SketchUp 8 in 10 Minutes, Sams, 2011.

9. Kalay, Y. E., Architecture's New Media: Principles, Theories, and Methods of ComputerAided Design. Cambridge, Massachusetts: The MIT Press, 2004.

10. Lane, D., Seery, N., Gordon, S., Promoting Creative Discovery and Mental Synthesis through Freehand Sketching. Visualizing Change - Graphics on the Horizon ASEE Engineering Design Graphics Division65th Mid-Year Conference October 3 - 6, 2010.

11. Lawson, B., What designers know. Oxford, Architectural Press, 2004.

12. Lipson, $\mathrm{H}$ and Shpitalni, M., Conceptual design and analysis by sketching, In AIDAM-97, 1997.

http://citeseerx.ist.psu.edu/viewdoc/summary?doi=10.1.1.17.6001 
13. Ma, C., Qin, S., Wang, H. \& Dai G., Modelling sketching primitives to support freehand drawing based on context awareness. Computing and Informatics, Vol. 29, 2010, 585-600.

14. Masry, M. \& Lipson, H., A Sketch-Based Interface for Iterative Design and Analysis of $3 D$ Objects, 2nd Eurographics Workshop on Sketch-Based Interfaces and Modeling, 2005.

15. Mawter, J., Thinking Skills, Humorous Texts and Literacy, ACCESS The National Journal of the Australian School Library Association, 2006.

16. Oh, Yeonjoo. Design Evaluator: Critiquing Freehand Sketches. MSc thesis, University of Washington, USA, 2004.

17. Peters, B., The Copenhagen Elephant House: A Case Study of Digital Design Processes. , Proceedings of the 28th Annual Conference of the Association for Computer Aided Design in Architecture (ACADIA), 2008, 134-41.

http://www.fosterandpartners.com/data/profile/rd/case/Foster_+_Partners_RD_Paper_Copenh agen Elephant House.pdf

18. Schumacher, P., Digital Hadid: Landscapes in Motion, Birkhauser, London 2004. http://www.patrikschumacher.com/Texts/digitalhadid.htm\#currentwork

19. Yu, J. \& Zhang, H., A Prototype Sketch-Based Architectural Design System with Behavior Mode, EUROGRAPHICS Workshop on Sketch-Based Interfaces and Modeling, (Eds.) van de Panne, M. \& Saund, E., 2007, pp. 1-7. 